\title{
Are Short-Lived Jobs Stepping Stones to Long-Lasting Jobs ?
}

B. Cockx and M. Picchio

Discussion Paper 2009-04

\section{Institut de Recherches Économiques et Sociales de l'Université catholique de Louvain}




\title{
Are Short-Lived Jobs Stepping Stones to Long-Lasting Jobs?*
}

\author{
Bart Cockx ${ }^{\dagger}$ and Matteo Picchio ${ }^{\ddagger}$
}

February 16, 2009

\begin{abstract}
This paper assesses whether short-lived jobs (lasting one quarter or less and involuntarily ending in unemployment) are stepping stones to long-lasting jobs (enduring one year or more) for Belgian long-term unemployed school-leavers. We proceed in two steps. First, we estimate labour market trajectories in a multispell duration model that incorporates lagged duration and occurrence dependence. Second, we simulate them to find that (fe)male school-leavers accepting a short-lived job are, within two years, 13.4 (9.5) percentage points more likely to find a long-lasting job than in the counterfactual in which they reject shortlived jobs to search longer for more stable positions.
\end{abstract}

Keywords: event history model, transition data, state dependence, short-lived jobs, stepping stone effect, long-lasting jobs.

JEL classification codes: C15, C41, J62, J64

${ }^{*}$ The authors acknowledge financial support from the Belgian Federal Science Policy Office (contract SO/10/073 and PAI P6/07) and intensive computing machines support from CISM, Université catholique de Louvain (FRFC 2.4502.05, Simulation numérique. Application en physique de l'état solide, océanographie et dynamique des fluides). Matteo Picchio is in addition grateful for the research grant he received from the Special Research Fund (FSR) of the Universite catholique de Louvain. We also wish to thank Muriel Dejemeppe, Rafael Lalive, Louis-André Vallet, Bas van der Klaauw, Bruno Van der Linden, Ingrid Van Keilegom, and the participants to the XXII and XXIII Italian National Conferences of Labour Economics in Napoli and Brescia, to the COST A23 conference in The Haugue (October 2007), to the VIII Belgian Day for Labour Economists in Louvain-la-Neuve (June 2008), to the EALE conference in Amsterdam (September 2008), to the QMSS2 Seminar in Oslo (October 2008), and to seminar in Ghent University (November 2008) for their comments.

${ }^{\dagger}$ Sherppa, Ghent University, Tweekerkenstraat 2, B-9000 Gent, Belgium; UCLouvain (IRES), Louvain-la-Neuve; IZA, Bonn ; CESIfo, Munich. E-mail: bart.cockx@ugent.be.

${ }^{\ddagger}$ IRES and Department of Economics, Université catholique de Louvain, Place Montesquieu 3, B1348 Louvain-la-Neuve, Belgium. E-mail: matteo.picchio@uclouvain.be. 


\section{Introduction}

Since the end of the 1980s, labour market regulations on temporary employment have been eased in many OECD countries, amongst which Belgium, ${ }^{1}$ while leaving labour market protection for open-ended employment hardly affected (OECD, 2004b). Research suggests that disadvantaged groups, such as youth, women, and long-term unemployed, excluded from employment by too strict regulations, may benefit most from this enhanced flexibility.

There is, however, a debate on whether the increased availability of temporary jobs facilitates the integration of these disadvantaged groups in regular stable employment or, in contrast, spurs the development of a secondary labour market, in which especially the most vulnerable of these disadvantaged workers get trapped in a cycle between temporary dead-end jobs and unemployment. This article aims at providing more insights on this debate by analysing the labour market transitions of long-term unemployed school-leavers in Belgium.

Economic theory provides ambiguous predictions with respect to this debate. On the one hand, accepting a short-term position may signal low ambition or skills reducing thereby the chances of conversion to a stable position. On the other hand, by accepting a short-term job a worker could also signal her motivation, acquire access to informal networks, and avoid deterioration of human capital, facilitating thereby the search for a longer lasting job. In addition, to the extent that the temporary position lasts long enough, a worker can acquire skills that may be useful in subsequent employment relationships.

The degree to which permanent employment is protected may also influence the stepping stone effect of temporary jobs, but again the theoretical predictions are ambiguous (Casquel and Cunyat, 2008; Ichino et al., 2008). On the one hand, the higher are firing costs for permanent jobs, the larger is the scope for using temporary jobs as a screening device, since firms attribute greater importance to the assessment of the quality of workers before locking themselves into a new open-ended employment relationship. On the other hand, higher firing costs may induce firms to use temporary workers as a mere flexibility buffer, if they make it impossible to adjust the number of regular employees during cyclical downturns.

Empirical evidence is more clearcut, at least if we restrict the analysis to the European labour market. ${ }^{2}$ Studies in the UK, the Netherlands, Italy, Sweden, and Belgium

\footnotetext{
${ }^{1}$ In 1997 and 2002 restrictions on employment in temporary work agencies were reduced and fixedterm contracts were made renewable (OECD, 2004b, pp. 119).

${ }^{2}$ For the US, findings are mixed. Most studies, based on non-experimental evaluation methods, find that short-term hirings by temporary help agencies lead to longer term employment and higher wages (e.g. Addison and Surfield, 2006; Andersson et al., 2007; Heinrich et al., 2007). However, based on an influential social experiment Autor and Houseman (2005) find that temporary help jobs boost shortterm earnings, but these gains are offset by lower earnings, less frequent employment, and potentially
} 
conclude that temporary employment, be it within fixed-term contracts or in temporary help agencies, are stepping stones to permanent employment. ${ }^{3}$ In Germany, Hagen (2003) finds supporting evidence for the stepping stone hypothesis of fixed-term contracts, but Kvasnicka (2008) can neither confirm nor deny this conclusion regarding employment in temporary help agencies. In contrast, Amuedo-Dorantes et al. (2006) report that in Spain accepting employment in temporary help agencies reduces the probability of being hired on a permanent basis. This dissonant result may be related to the fact that the Spanish employment protection legislation for regular employment is regarded to be one of the strictest in the EU (OECD, 2004b): the use of temporary workers as a flexibility buffer rather than a screening device seems to dominate in that case. Finally, in line with this negative finding, Gagliarducci (2005) and García Pérez and Muñoz-Bullón (2007) report that in Italy and Spain the conversion rate from temporary to permanent jobs decreases with the number of jobs experienced in the past. It follows thereby that temporary jobs are more likely to be stepping stones to permanent positions at the beginning of the career than later on.

The existing empirical studies contain, however, some drawbacks that we try to address. First, these studies aim at determining whether or not initial job insecurity leads to more job security later on. ${ }^{4}$ However, being employed with an open-ended contract is an imperfect indicator of job security, since it does not guarantee that a job is effectively long-lasting. This depends on the institutional environment. ${ }^{5}$ For instance, in Belgium open-ended contracts always start with a trial period during which an employer can end a contract at low costs. ${ }^{6}$ For white collar workers this trial period can last up to six months. ${ }^{7}$ For blue collar workers the trial period is much shorter (between 1 and 2 weeks), but their employment protection in open-ended contracts is also much weaker: maximum 35 days of notice payments if job experience is less than 5 years, while this is never less than 3 months for white collar workers. In this research we therefore propose to use an alternative measure of job security that is based on the effective job tenure. In the empirical analysis discussed below, job security is attained if a worker finds a job that lasts one year or more. ${ }^{8}$ We label these jobs as "long-lasting".

Another drawback of existing studies is that, depending on the institutional context, fixed-term contracts and employment in temporary work agencies may be rela-

\footnotetext{
higher welfare recidivism over the next one to two years.

${ }^{3}$ See Booth et al. (2002), Zijl et al. (2004), Larsson et al. (2005), Berton et al. (2007), Göbel and Verhofstadt (2008), Ichino et al. (2008), and Picchio (2008).

${ }^{4} \mathrm{Job}$ security is regarded as a central dimension of job quality which the Lisbon European council set as one of the main goals of the Union's employment strategy (European Commission, 2001).

${ }^{5}$ Note that this complicates the comparison of the findings across countries.

${ }^{6}$ Maximum 7 days of notice payments.

${ }^{7}$ The trial period can be up to 12 months for high paid jobs, but this concerns only very few jobs retained in the analysis below.

${ }^{8} \mathrm{We}$ will justify the choice of this threshold below.
} 
tively long-lasting. In the late 1990s, most of the OECD countries had no limits on the maximum duration and number of renewals of temporary jobs (OECD, 1999, § 2). In Belgium, a worker may conclude maximum four fixed-term contracts of a duration of minimum 3 months and maximum 2 years (OECD, 2007). As a consequence, the non-conversion to an open-ended contract is not necessarily identified with a situation of precarious employment. In addition, precarious employment is neither identified with a situation in which some workers voluntarily choose to cycle between temporary jobs. To overcome these criticisms, we do not investigate the stepping stone effect of accepting a short-term employment contract, ${ }^{9}$ but rather of accepting a "short-lived job", i.e. jobs lasting one quarter or less that are involuntarily interrupted. ${ }^{10}$ By restricting our analysis to short-lived jobs, we aim at estimating a lower bound for the conversion rate of temporary jobs to long-lasting jobs, taken as a measure of job security. ${ }^{11}$ Moreover, by restricting to very short-lived jobs, we obtain more insight in the causal mechanism of the conversion rate to long-lasting jobs: signaling or informal networks are then more likely determinants than human capital formation, since the latter requires more time.

The estimation of the stepping stone effect of short-lived jobs is realized in two steps. First, we estimate the complete labour market trajectory of all sampled workers, i.e long-term unemployed school-leavers. Subsequently, we investigate whether workers who accept a short-lived job (the treatment) are more or less likely to enter a long-lasting job (the successful outcome) than if they always rejected such jobs and continued job search until finding a more stable position. Since the treatment effect is a complicated function of the estimated parameters, we can only find an answer to this question on the basis of simulations. Moreover, since the treatment effect can be heterogeneous in terms of observed and unobserved characteristics, we do not only simulate the average treatment effect on the treated (ATT), but also the complete distribution of the individual treatment effects (Heckman et al., 1997).

The credibility of our approach crucially hinges on the realism of the model in the first step. We distinguish between three states: insured unemployment, employment, and an absorbing censoring state for all remaining states. ${ }^{12}$ We explicitly model jobto-job transitions. On the basis of a model similar to ours, estimated on a sample of Australian school-leavers, Doiron and Gørgens (2008) find that labour market transi-

\footnotetext{
${ }^{9}$ We cannot identify the type of employment contract in the data.

${ }^{10} \mathrm{We}$ identify an involuntary interruption by one that ends in insured unemployment. In Belgium, workers are not entitled to unemployment benefits if they voluntarily quit a job.

${ }^{11}$ To the extent that job-to-job transitions are voluntary, one could argue that we should consider employment security instead of job security as an indicator of success. However, sticking to an indicator of job security should provide us with a conservative measure of employment security.

${ }^{12} \mathrm{We}$ model the censoring state as absorbing in order to reduce the dimensionality of the computational problem. This contrasts with Doiron and Gørgens (2008), who model out of the labour force as a separate state, but they do not consider job-to-job transitions.
} 
tions of youth are characterized by a complex form of state dependence, depending not only on the history in the current labour market state, but also on past history. We accommodate to these concerns by estimating a mixed proportional hazard (MPH) model with competing risks of exit, in which we allow the order, the type, and the duration of the previous spell to proportionally shift the baseline hazards. ${ }^{13}$ The selection on unobservables is controlled for on the basis of a discrete distribution with an unknown number of mass points in which the correlation structure is completely flexible (Heckman and Singer, 1984). Horny and Picchio (2009) prove that all the parameters of such a model are non-parametrically identified. Moreover, since in this empirical application we observe multiple spells, we impose restrictions on the form of the hazards across spells, and we condition on exogenous time-varying explanatory variables, we speculate on the basis of the existing literature (Brinch, 2007; Gaure et al., 2008; Horny and Picchio, 2009) that the model is over-identified and that the proportionality assumption is therefore not crucial for identification. The estimation procedure corresponds to the one that Gaure et al. (2007) have validated in extensive Monte Carlo simulations.

Section 2 describes the data on which the analysis is based. Section 3 discusses the specification of the econometric model. The estimation results are reported and commented in Section 4. Section 5 describes the simulation on the basis of which we assess, first, the goodness-of-fit of the model and, subsequently, the stepping stone effect. Section 6 concludes. Details concerning the simulation procedure and further estimation and simulation results are provided in an internet appendix that can be downloaded from http://users.ugent.be/ bcockx/Appendix-CPa.pdf.

\section{The Data}

The empirical analysis is conducted on administrative records gathered by the Crossroads Bank for Social Security (CBSS). ${ }^{14}$ The CBSS merges data from the different Belgian Social Insurance institutions and allows thereby to construct the quarterly labour market history of all Belgian workers. As explained in the Introduction, this research is concerned with disadvantaged youth. The sample contains all Belgian school-leavers, aged between 18 and 25 years, who, in 1998, were still unemployed nine months after graduation. In Belgium, after this "waiting period" of nine months, school-leavers are entitled to unemployment benefits (UB) and, as a consequence, they

\footnotetext{
${ }^{13}$ Doiron and Gørgens (2008) specify lagged occurrence and lagged duration dependence as the cumulative number and duration of spells since first entry in the labour force. However, we are not aware of any identification result for such a model.

${ }^{14}$ See http://www.ksz.fgov.be/En/CBSS.htm.
} 
show up for the first time in the administrative records of the CBSS. ${ }^{15}$ By sampling from a population of school-leavers we drastically simplify initial conditions problems in the analysis of lagged labour market dependence, since nobody in the sample had any labour market experience prior to the sampling date. Nevertheless, the fact that all sampled individuals have been unemployed for nine months since graduation does complicate the analysis. We will discuss in Subsection 3.3 how we deal with this complication.

The eventual sample contains 8,921 women and 6,627 men. The administrative records allowed us to reconstruct the quarterly (un)employment history of these workers for a period of (maximum) four years, from the beginning of 1998 until the end of 2001. In the analysis we distinguish between three mutually exclusive labour market states occupied at the end of each quarter: unemployed as UB recipient $(u)$, employed $(e)$, and an absorbing censoring state $(a)$. This censoring state is accessed if the individual leaves the labour force, enters a training programme, returns to school, or is sanctioned and looses her entitlement to UB. We consider five possible transitions between these states: $(u, e),(u, a),(e, u),(e, a)$ and, since the data contain a firm indicator, job-to-job transitions $(e, e)$.

Table 1 reports descriptive statistics on the number of observed spells at individual level. Individuals occupy on average 2.5 different labour market states during the four year observation window and a maximum of 12. Men are more mobile than women: $39 \%$ of the men in the sample experience at least 3 spells, whereas only $33 \%$ of the women. This multi-spell information is exploited to infer the impact of the lagged labour market outcomes on the subsequent transition intensities. Figure A-1 in Internet Appendix A-3 reports, by gender, the absolute frequencies of transitions that are observed in the data. Figure A-2 reports similar figures but decomposing jobs according to their duration.

Table 2 displays summary statistics of the explanatory variables contained in the data. They can be decomposed into three groups: time-invariant covariates fixed at the sampling date, spell specific variables fixed at the value attained at the start of the corresponding spell, but varying across spells, and time-varying covariates whose values can change every quarter. The statistics of spell specific and time-varying explanatory variables are reported at the sampling date, except for the firm characteristics, which are reported at the start of the first job spell. Summary statistics of the values of the time-varying variables at the beginning of subsequent labour market spells are reported in Internet Appendix A-3, Table A-1. ${ }^{16}$

Nationality, region of residence, and education are the time-invariant covariates.

\footnotetext{
${ }^{15}$ Note that the entitlement of school-leavers to UB is a-typical, but similar schemes exist in Denmark, Greece, Luxembourg, and Czech Republic although usually with stricter eligibility criteria (OECD, 2004a).

${ }^{16}$ Tables A-2 and A-3 in the same internet appendix present descriptive statistics of short-lived jobs and long-lasting jobs, respectively for men and women.
} 
Table 1: Individual Observations by Number of Observed Spells and Gender

\begin{tabular}{|c|c|c|c|c|}
\hline \multirow[b]{2}{*}{ \# of spells (Unemployment + job spells) } & \multicolumn{2}{|c|}{ Male } & \multicolumn{2}{|c|}{ Female } \\
\hline & $\begin{array}{l}\text { Absolute } \\
\text { frequency }\end{array}$ & $\begin{array}{l}\text { Relative } \\
\text { frequency } \\
(b)\end{array}$ & $\begin{array}{l}\text { Absolute } \\
\text { frequency } \\
(a)\end{array}$ & $\begin{array}{l}\text { Relative } \\
\text { frequency }^{(b)}\end{array}$ \\
\hline 1 & 6,627 & $100.0 \%$ & 8,921 & $100.0 \%$ \\
\hline 2 & 3,901 & $58.9 \%$ & 4,405 & $49.4 \%$ \\
\hline 3 & 2,552 & $38.5 \%$ & 2,917 & $32.7 \%$ \\
\hline 4 & 1,513 & $22.8 \%$ & 1,755 & $19.7 \%$ \\
\hline 5 & 876 & $13.2 \%$ & 1,028 & $11.5 \%$ \\
\hline 6 & 492 & $7.4 \%$ & 577 & $6.5 \%$ \\
\hline 7 & 265 & $4.0 \%$ & 326 & $3.7 \%$ \\
\hline 8 & 132 & $2.0 \%$ & 181 & $2.0 \%$ \\
\hline 9 & 70 & $1.1 \%$ & 95 & $1.1 \%$ \\
\hline More than 9 & 49 & $0.8 \%$ & 70 & $0.8 \%$ \\
\hline Total observed spells & \multicolumn{2}{|c|}{16,477} & \multicolumn{2}{|c|}{20,275} \\
\hline Average spells per individual & \multicolumn{2}{|c|}{2.49} & \multicolumn{2}{|c|}{2.27} \\
\hline Maximum number of individual spells & \multicolumn{2}{|c|}{12} & \multicolumn{2}{|c|}{12} \\
\hline \multicolumn{5}{|c|}{$\begin{array}{l}\text { (a) Number of individuals in the sample who experience the corresponding number of different } \\
\text { spells. } \\
\text { (b) This frequency is the ratio of the number of individuals who experience the corresponding } \\
\text { number of different spells to the total number of individuals who entered the sample. }\end{array}$} \\
\hline
\end{tabular}

Since the sample consists of long-term unemployed, sections of the population with a high unemployment risk are more represented in the sample than in the population as a whole: foreigners, low schooled youth and, since the unemployment rate in Flanders is much lower, those living in Wallonia and Brussels. ${ }^{17}$ The high share of youth living in Wallonia is especially striking: roughly two thirds of the sample lives in Wallonia, whereas only one third of the total Belgian population has its residence in Wallonia.

The set of spell specific explanatory variables contains age, quarter of entry into the spell, household position, the monthly amount of unemployment benefits, and a set of sector and firm size indicator variables. Two variables are conditioned upon in the empirical analysis, but not reported in Table 2 since their value is zero at the sampling date: the length of the previous labour market spell and an indicator for the previous spell type.

We distinguish between three types of household positions: head of household, single or cohabitant. These categories determine together with age the level of the flat UB rate to which the unemployed school-leavers are entitled to after the higher mentioned waiting period. In 2000 , the monthly benefit level varied between $307 €$ for cohabitants (more than 18 years old) not in charge of other members in the household and $790 €$ for household heads. The majority of the sampled individuals (79\%) is cohabitant. This reflects that most youth is still living in their parents' home.

School-leavers who worked at least one year during a time window of 18 months

\footnotetext{
${ }^{17}$ Belgium is divided into three regions: Flanders, the Flemish-speaking region in the North, Wallonia, the French-speaking region in the South, and Brussels.
} 
Table 2: Summary Statistics by Gender

\begin{tabular}{|c|c|c|c|c|}
\hline & \multicolumn{2}{|c|}{ Male } & \multicolumn{2}{|c|}{ Female } \\
\hline & Mean & St.Dev. & Mean & St.Dev. \\
\hline \multicolumn{5}{|c|}{ Time-invariant covariates } \\
\hline \multicolumn{5}{|l|}{ Nationality } \\
\hline Belgian & .891 & .312 & .879 & .326 \\
\hline Non-Belgian EU & .052 & .222 & .054 & .226 \\
\hline Non EU & .057 & .232 & .067 & .250 \\
\hline \multicolumn{5}{|l|}{ Education } \\
\hline Primary ( 6 to 9 years of schooling) & .121 & .326 & .079 & .269 \\
\hline Lower secondary (9 to 12 years) & .280 & .449 & .226 & .419 \\
\hline Higher secondary (12 to 16 years) & .422 & .494 & .481 & .500 \\
\hline Higher education (16 years or more) & .126 & .332 & .173 & .378 \\
\hline Other & .009 & .094 & .008 & .088 \\
\hline Unknown & .042 & .201 & .033 & .178 \\
\hline \multicolumn{5}{|l|}{ Region of residence } \\
\hline Flanders & .201 & .401 & .245 & .430 \\
\hline Wallonia & 674 & .469 & .641 & .480 \\
\hline Brussels & .125 & .331 & .114 & .317 \\
\hline \multicolumn{5}{|c|}{ Time-variant spell-specific covariates at sampling date } \\
\hline Age & 20.5 & 1.96 & 20.4 & 1.97 \\
\hline Monthly unemployment benefits (in €) & 332.9 & 120.5 & 344.0 & 139.0 \\
\hline \multicolumn{5}{|l|}{ Quarter of entry } \\
\hline January-February-March & .081 & .273 & .071 & .258 \\
\hline April-May-June & .660 & .474 & .689 & .463 \\
\hline July-August-September & .166 & .372 & .164 & .371 \\
\hline October-November-December & .093 & .290 & .076 & .264 \\
\hline \multicolumn{5}{|l|}{ Household Position } \\
\hline Head of household & .077 & .266 & .108 & .311 \\
\hline Single & .134 & .341 & .101 & .302 \\
\hline Cohabitant & .789 & .408 & .791 & .407 \\
\hline \multicolumn{5}{|l|}{ Firm size (a) $^{(2)}$} \\
\hline$[1,20)$ employees & .272 & .445 & .254 & .435 \\
\hline$[20,50)$ employees & .063 & .243 & .071 & .257 \\
\hline$[50,100)$ employees & .044 & .205 & .044 & .205 \\
\hline$[100,500)$ employees & .135 & .342 & .142 & .349 \\
\hline 500 or more employees & .486 & .500 & .489 & .500 \\
\hline \multicolumn{5}{|l|}{ Sector ${ }^{(\mathrm{a})}$} \\
\hline Agriculture & .029 & .168 & .018 & .133 \\
\hline Industry \& Mining & .086 & .281 & .039 & .193 \\
\hline Building \& Energy & .082 & .274 & .011 & .103 \\
\hline Wholesale \& Retail trade & .164 & .370 & .183 & .387 \\
\hline Credit \& Insurance & .014 & .119 & .017 & .130 \\
\hline Business services & .420 & .494 & .343 & .475 \\
\hline Other services \& Public admin. & .205 & .403 & .390 & .488 \\
\hline \multicolumn{5}{|c|}{ Time-variant covariates at sampling date } \\
\hline Local unemployment rate & .184 & .069 & .269 & .085 \\
\hline Observations & & 27 & & \\
\hline
\end{tabular}

(a) Sector and firm size figures refer to the start of the first job spell. 
become entitled to higher UB if they are laid off. ${ }^{18}$ There are some workers in the sample who receive these higher UB when they experience a subsequent unemployment spell. In order to account for the adverse incentive effects related to these higher UB, we explicitly included the monthly UB level as an explanatory variable. In addition, we explicitly take into account that, if one is not the head of the household, these higher UB drop to a lower level after one year. As a consequence, to the extent that this drop is anticipated, this affects the profile of the duration dependence of the transition rate from unemployment. Following Meyer (1990), we explicitly control for this by including, for those individuals who can suffer UB drops (the dummy declining benefits), four time-varying indicator variables (not reported in Table 2). If $\tau$ denotes the number of quarters remaining before benefits fall to a lower level, we define these variables as follows: $U I 1=1$ if $\tau=1$, and 0 otherwise; $U I 2=1$ if $\tau \leq 2$, and 0 otherwise; $U I 3=1$ if $\tau \leq 3$, and 0 otherwise; $U I 4=1$ if $\tau \leq 4$, and 0 otherwise. In the empirical analysis below, the coefficient of $U I 1$ captures the marginal effect of going from 2 quarters to 1 quarter before the benefit drop. The coefficients of the other variables have a similar interpretation.

The firm size indicators are created on the basis of the number of employees in the reference worker's firm. We distinguish between five firm size types. Almost one half of the subsample of those who find a job are employed in large firms and more than one quarter in small firms. On the basis of the NACE nomenclature ${ }^{19}$ and a 2digit information, we distinguish between seven firm sectors. Most of the workers is employed in "Business services". This sector comprises several types of services provided to firms: cleaning, call-centre activities, labour recruitment, counselling, advertising, and accounting. The data do not allow to further decompose this sectoral information.

Finally, in order to take into account the state of the labour market, the local unemployment rate is modelled as a time-varying explanatory variable. Since in Belgium no statistic exists on the local unemployment rate following the standard ILO definition, we rely on a non-standard statistic provided by the Belgian Unemployment Agency (ONEM). This statistic reports the fraction of the population insured against the risk of unemployment (thereby excluding civil servants) which is entitled to UB. This usually results in a higher unemployment rate than the one obtained with the ILO definition. At the sampling date in 1998, the average local unemployment rate for men and women is $18.4 \%$ and $26.9 \%$, compared to $7.7 \%$ and $11.6 \%$ according to the standard ILO definition (http://epp.eurostat.ec.europa.eu).

\footnotetext{
${ }^{18}$ See http://www.onem.be for more details.

${ }^{19}$ See http://ec.europa.eu/comm/competition/mergers/cases_old/index/nace_all.html for a detailed list of NACE codes.
} 


\section{The Econometric Model}

In the Introduction we announced that the analysis is conducted in two steps. In a first step we estimate a multi-state multi-spell duration model in which the nature and the duration of the labour market state occupied in the past are allowed to influence the duration of stay in the current state. In a second step (Section 5), we run a microsimulation exercise on this econometric model to identify whether short-lived jobs are stepping stones to long-lasting jobs.

This section focuses on econometric issues of the first step, makes the model specification explicit, discusses the identification of the structural parameters of interest, and elucidates the main steps in the construction of the likelihood function.

\subsection{The Specification of Transition Intensities}

Since we only observe the labour market state occupied at the end of each quarter, the observed data are grouped in discrete time intervals. To avoid the dependency of parameters to the time unit of observation (Flinn and Heckman, 1982), we follow van den Berg and van der Klaauw (2001) and specify the discrete-time process as in a grouped continuous-time model. If $s=1, \ldots, S$ denotes the spell order, counting the number of times a particular labour market state $(u$ or $e$ ) is occupied, the transition intensity in spell $s$ from the origin state $j$ to the destination state $k$ is denoted by $\theta_{j k}^{s}$, with the ordered pair $(j, k) \in \mathscr{Z}=\{(u, e),(u, a),(e, e),(e, u),(e, a)\}$. During spell $s$ started at time $\tau_{s}$ (with $\tau_{s} \in \mathbb{N}_{0}$ ) and after $t_{s}$ quarters in state $j$ (with $t_{s} \in \mathbb{N}_{0}$ ), the transition intensity from $j$ to $k$ is specified in the following MPH form:

$$
\theta_{j k}^{s}\left(t_{s} \mid \mathbf{x}_{j k}\left(\tau_{s}+t_{s}\right), v_{j k}\right)=\exp \left[\gamma_{j k}\left(t_{s}\right)+\boldsymbol{\beta}_{j k}^{\prime} \mathbf{x}_{j k}\left(\tau_{s}+t_{s}\right)\right] v_{j k}^{s}
$$

for $(j, k) \in \mathscr{Z}$, where $\exp \left[\gamma_{j k}\left(t_{s}\right)\right]$ is the piecewise constant baseline hazard capturing the duration dependence; $v_{j k}^{s}$ is the spell- and transition-specific individual heterogeneity, a positive random number; $\mathbf{x}_{j k}\left(\tau_{s}+t_{s}\right)$ is a $K_{j k}$ dimensional vector of time-invariant and time-variant covariates controlling for observed heterogeneity at the transition quarter $\left(\tau_{s}+t_{s}\right)$ and including the length and type (unemployed or not) of the preceding labour market spell. The associated and conformable parameter vector to be estimated is $\boldsymbol{\beta}_{j k}$.

We impose in (1) that $\gamma_{j k}\left(t_{s}\right)$ and $\boldsymbol{\beta}_{j k}$ are fixed across spells. This is not required for identification (Horny and Picchio, 2009), but it reduces the computational burden, increases the precision of the parameter estimates and, by imposing more structure, identification will intuitively depend less on the MPH specification. We restrict the specification even further in that the order $s$ of the spell just shifts the baseline transition intensity proportionally across subsequent spells or even not at all if the absorbing 
censoring state $(a)$ is the destination: ${ }^{20}$

(i) $v_{j a}^{s}=v_{j a}$ for $j=u, e$ and $s=1, \ldots, S$;

(ii) $v_{j k}^{s}=v_{j k} c_{j k}^{s}$, for $(j, k) \in\{(u, e),(e, e),(e, u)\}$, where $c_{j k}^{s}=c_{j k}^{3}$ for $s=$ $4, \ldots, S$. The scaling factors $c_{j k}^{1}$ are normalized to 1 for each $(j, k) \in\{(u, e)$, $(e, e),(e, u)\}$.

To avoid parametric assumptions on the distribution of the unobserved heterogeneity, we follow Heckman and Singer (1984) and assume that the vector $\mathbf{v} \equiv$ $\left[v_{u e}, v_{u a}, v_{e e}, v_{e u}, v_{e a}\right]$ is a random draw from a discrete distribution function with a finite and (a priori) unknown number $M$ of support points. The probabilities associated to the mass points sum to one and, $\forall m=1, \ldots, M$, are denoted by

$$
p_{m}=\operatorname{Pr}\left(v_{u e}=v_{\text {uem }}, v_{\text {ua }}=v_{\text {uam }}, v_{\text {ee }}=v_{\text {eem }}, v_{\text {eu }}=v_{\text {eum }}, v_{\text {ea }}=v_{\text {eam }}\right) \equiv \operatorname{Pr}\left(\mathbf{v}=\mathbf{v}_{m}\right)
$$

and specified as logistic transforms:

$$
p_{m}=\frac{\exp \left(\lambda_{m}\right)}{\sum_{g=1}^{M} \exp \left(\lambda_{g}\right)} \quad \text { with } \quad m=1, \ldots, M \quad \text { and } \quad \lambda_{M}=0 .
$$

A pre-specified low number of support points may result in substantial bias. We therefore choose, as suggested by Gaure et al.'s (2007) Monte Carlo simulations, the $M$ number of support points to minimize the Akaike Information Criterion (AIC).

\subsection{Identification}

In order to determine the stepping stone effect of short-lived jobs we must have a model that credibly identifies the causal impact of the labour market history on the current labour market trajectory. The determination of this causal impact crucially depends on the capacity to control for sources of endogeneity. We attempt to control for four sources of endogeneity: (i) unobserved heterogeneity; (ii) endogenous censoring; (iii) endogeneity induced by time-varying variables; (iv) initial conditions.

It is well known that the failure to control for (un)observed individual characteristics leads to inconsistent estimates of the structural parameters of interest, in particular of the baseline hazard and the lagged occurrence and lagged duration dependence. The selection on unobservables is controlled for on the basis of a discrete distribution with an unknown number of mass points in which the correlation structure is completely flexible (Heckman and Singer, 1984). Horny and Picchio (2009) prove that, if one imposes the MPH structure, the heterogeneity distribution is non-parametrically identified together with the structural parameters of the model, including the lagged

\footnotetext{
${ }^{20}$ Note that, by way of this factor of proportionality and the type (unemployed or not) of the preceding labour market spell, we specify lagged occurrence dependence.
} 
occurrence and lagged duration dependence. ${ }^{21}$ Moreover, since in this empirical application we observe multiple spells, we impose restrictions on the specification of the hazard across spells, ${ }^{22}$ and we condition on exogenous time-varying explanatory variables, we speculate on the basis of the existing literature (Brinch, 2007; Gaure et al., 2008; Horny and Picchio, 2009) ${ }^{23}$ that the model is over-identified and that identification is therefore not only achieved by the proportionality assumption. A concern nevertheless remains, since the higher mentioned identification result assumes that the data are measured in continuous time, whereas our data are quarterly. Gaure et al. (2007) however report from an extensive Monte Carlo analysis ${ }^{24}$ that, in practice, the discrete-time measurement still allows to robustly recover the true structural parameters from the observed data, to the extent that the discreteness of data measurement is explicitly taken into account in setting up the likelihood function. This is what we do in Section 3.3.

We focus on the transitions between two labour market states: unemployment $(u)$ and employment in the same firm $(e)$. However, as pointed out by van den Berg et al. (1994) and van den Berg and Lindeboom (1998), if there are unobserved characteristics affecting both the labour market transitions of interest $((u, e),(e, u)$ and $(e, e))$ and the transitions to other destinations, this may lead to inconsistent estimates of the parameters determining the transitions of interest. This is why we explicitly specify an absorbing censoring state $(a)$ the transitions to which $((u, a)$ and $(e, a))$ may depend on unobserved variables that are correlated with the other unobservables.

In the two preceding points we discussed how we can correct for the selectivity bias induced by time-constant determinants of the labour market transitions. Event history models can, however, also easily take time-varying factors of transitions into account if their time-path is observed. In the previous section we discussed which time-varying variables we condition upon in the analysis and why.

A final point of concern is the initial conditions problem common in dynamic models with lagged dependent variables. In general, the probability of being observed in the labour market state occupied at the sampling date is determined by the history of labour market transitions before this date. Since this history is typically not observed, it is usually difficult to derive the correct expression for this probability, unless one

\footnotetext{
${ }^{21}$ The proof is an extension of those given by Honoré (1993), Omori (1998), and Abbring and van den Berg (2003a).

${ }^{22}$ The model would be identified even if all transition intensities were spell-specific. We only allow for a proportional shift across spells.

${ }^{23}$ See also Bhargava (1991) and Mroz and Savage (2006) who discuss how the time-variation of exogenous variables helps identifying the causal impacts of endogenous variables in dynamic discrete time panel data models.

${ }^{24}$ To our knowledge only Ridder (1990) explicitly treats the identification of grouped data, but only in a single-spell and single-risk framework. With discrete duration data, a sufficient additional condition for identification is the presence of at least one continuous covariate that spans the whole set of real numbers, instead of one covariate taking on only two values in the continuous case.
} 
makes strong assumptions, such as stationarity. Moreover, since this probability is, in general, a function of the parameters of interest, its misspecification is a source of bias. Here this problem is however simplified, since we know that all sampled individuals entered the labour force nine months before the sampling date. The probability of being observed at the sampling date is therefore given by the joint probability of entering unemployment after graduation and remaining unemployed during the subsequent three quarters. The only parameters of interest involved in this expression are therefore those determining the transition rate from unemployment and not those from employment. The initial conditions problem therefore boils down to a left censoring problem in a single spell framework.

We compare two solutions to this problem: the conditional likelihood approach proposed by Ridder (1984) and the approximate solution suggested by Heckman (1981) for dynamic discrete choice models implemented by Gritz (1993) in a duration model. We prefer these approaches to the more efficient method followed by Flinn and Heckman (1982), since they are more robust by not requiring the strong assumptions that the economic environment is stationary and in equilibrium. Heckman's (1981) solution is more flexible than Ridder's (1984), but we prefer the latter to the former, since in Heckman's (1981) approach one looses the structural interpretation of the parameters regarding the first transition from unemployment and, hence, these are no longer comparable to the second transition from unemployment. This choice is justified on the basis of a Vuong (1989) likelihood ratio test of strictly non-nested models: neither model can be rejected against the other according to this test. We will show below in more details how these initial conditions modify the likelihood function.

\subsection{The Likelihood Function}

In the derivation of the likelihood we first ignore the initial conditions problem and assume that the sample is drawn at the start of the unemployment spell right after graduation. In a second step, we explain what we should modify to take into account that all workers are already three quarters unemployed at the sampling date.

We start with the derivation of the individual contributions of each spell to the likelihood function. As mentioned in the previous section, we explicitly take into account that the data are measured in discrete time. The contribution of a spell $s$ with origin state $j$ that is incomplete because right censored at the end of the observation period is simply given by the survivor function in that state until the end of the observation period:

$$
L_{i s}^{c}\left(t_{s} \mid \mathbf{x}_{j}, \mathbf{v}_{j}^{s} ; \Theta_{j}\right) \equiv S_{j}\left(t_{s} \mid \mathbf{x}_{j}, \mathbf{v}_{j}^{s}\right)=\prod_{d=1}^{t_{s}} \exp \left\{-\sum_{(j, k) \in \mathscr{J}} \theta_{j k}^{s}\left(\tau \mid \mathbf{x}_{j k}\left(\tau_{s}+d\right), v_{j k}^{s}\right)\right\}
$$


where $\mathscr{J}=\mathscr{E} \equiv\{(e, e),(e, u),(e, a)\}$ if $j=e$ and $\mathscr{J}=\mathscr{U} \equiv\{(u, e),(u, a)\}$ if $j=u, \Theta_{j}$ is the set of parameters if the origin state is $j$, and $\mathbf{x}_{j}$ and $\mathbf{v}_{j}^{s}$ collect the $\mathbf{x}_{j k}\left(\tau_{s}+t_{s}\right)$ 's and the $v_{j k}^{s}$ 's with $(j, k) \in \mathscr{J}$.

Using the same notation, the contribution to the likelihood function of a complete spell $s$ with origin state $j$ and destination state $k$ is derived in Appendix A-1 and takes the following form:

$$
\begin{aligned}
& L_{i s}\left(t_{s} \mid \mathbf{x}_{j}, \mathbf{v}_{j}^{s} ; \Theta_{j}\right)=\frac{\theta_{j k}^{s}\left(t_{s} \mid \mathbf{x}_{j k}\left(\tau_{s}+t_{s}\right), v_{j k}^{s}\right)}{\sum_{(b, c) \in \mathscr{J}} \theta_{b c}^{s}\left(t_{s} \mid \mathbf{x}_{b c}\left(\tau_{s}+t_{s}, v_{b c}^{s}\right)\right.} \\
& \times\left[S_{j}\left(t_{s}-1 \mid \mathbf{x}_{j}, \mathbf{v}_{j}^{s}\right)-S_{j}\left(t_{s} \mid \mathbf{x}_{j}, \mathbf{v}_{j}^{s}\right)\right] .
\end{aligned}
$$

Conditional on the unobserved covariates, individual $i$ 's contribution to the likelihood function is given by the product over the individual $i$ 's single spell contributions. Let $L_{i}\left(\mathbf{t}_{i} \mid \mathbf{x}_{i}, \mathbf{v} ; \Theta\right)$ denote this product, where $\mathbf{t}_{i}$ collects all the individual $i$ 's labour market durations and $\mathbf{x}_{i}$ and $\mathbf{v}$ the associated set of observed and unobserved covariates. Integrating out the unobserved heterogeneity $\mathbf{v}$ on the basis of the abovementioned discrete distribution yields the unconditional individual contribution to the likelihood function:

$$
L_{i}\left(\mathbf{t}_{i} \mid \mathbf{x}_{i} ; \Theta\right)=\sum_{m=1}^{M} p_{m} L_{i}\left(\mathbf{t}_{i} \mid \mathbf{x}_{i}, \mathbf{v}_{m} ; \Theta\right)
$$

The log-likelihood function sums the logarithm of this expression over all the individuals in the sample.

We now turn to the modification required to deal with the initial conditions problem. Ridder (1984) considers the likelihood conditional on being observed at the sampling date. The probability of being observed at the sampling date is given by the joint probability of entering unemployment after graduation and remaining unemployed during the subsequent three quarters. The probability of entering unemployment can, however, be ignored if we assume that it is proportional in observed and unobserved characteristics. The required modification is therefore just a division of the individual contribution in (4) by the probability of surviving three quarters in unemployment averaged over the unobserved heterogeneity distribution:

$$
L_{i}^{0}\left(\mathbf{t}_{i} \mid \mathbf{x}_{i} ; \Theta\right)=\frac{L_{i}\left(\mathbf{t}_{i} \mid \mathbf{x}_{i} ; \Theta\right)}{\sum_{m=1}^{M} p_{m} S_{u}\left(3 \mid \mathbf{x}_{u}, \mathbf{v}_{u}\right)} .
$$

The correction for initial conditions is carried out by the presence of $S_{u}$ in the numerator and denominator of (5): it corrects for different unobserved propensities to leave among different subpopulations and ensures thereby that, conditional on this differential sorting, the impact of observed characteristics remains proportional with 
duration.

Heckman's (1981) solution to the initial conditions boils down to constructing the likelihood on the basis of individual contributions of the form expressed in (4) in which the parameters of the transition intensities from the first unemployment spell, $\theta_{u e}^{1}$ and $\theta_{u a}^{1}$, are no longer constrained to be equal to those from the subsequent unemployment spells. ${ }^{25}$ The drawback of this approach is that the estimated transitions from the first unemployment spell do not therefore have a structural interpretation, since they are biased by the stock sampling.

\section{Estimation Results}

We focus the discussion of the estimation results on those factors that matter for the determination of the stepping stone effect of short-lived jobs: current duration dependence and lagged occurrence and duration dependence related to the transitions between the two labour market states of interest: $u$ and $e$. Since the parameters determining the transition intensities to the absorbing censoring state $a$ are not of direct interest, they are reported in the internet appendix.

The main results discussed in this section are based on the model which uses Ridder's (1984) correction for initial conditions. On the basis of a Vuong (1989) test, modified to permit AIC log-likelihood penalties, we cannot reject this benchmark model against the one based on Heckman's (1981) approach at a $p$-value of 0.305 for men and 0.140 for women. Moreover, as it can be verified in Table A-13 in Internet Appendix A-3, the parameter estimates of interest regarding the lagged duration and occurrence dependence are in line with those of the benchmark model.

The model we report here is one in which dependence on lagged duration is specified log-linearly. In a robustness analysis we also allowed this dependence to be piecewise continuous with two knots, the first one at two quarters and the second one at one year of lagged duration. We could not reject the null hypothesis of a constant slope, both for men and women. ${ }^{26}$

\subsection{Current Duration Dependence}

Figure 1 displays the patterns of the duration dependence of three transition rates: $(u, e),(e, e)$ and $(e, u) .{ }^{27}$ The baseline transition from unemployment to employment, reported in the upper panel, exhibits strong negative duration dependence up to the $7^{\text {th }}$ quarter and is roughly constant thereafter. This contrasts with the results of Cockx

\footnotetext{
${ }^{25}$ Note that the baseline transition intensities of the first three quarters are not identified, since no-one in the sample leaves unemployment within the first three quarters.

${ }^{26}$ The $p$-values are 0.877 for men and 0.120 for women.

${ }^{27}$ The point estimates and standard errors are reported in Table A-4 in Internet Appendix A-3.
} 
and Dejemeppe (2005), who cannot reject for young men aged 28 years or younger a constant profile of the baseline hazard rate from unemployment. However, this finding could follow from their incapacity to distinguish between transitions to employment and to other destinations: even if parameter estimates are not very precise, Table A-4 in Internet Appendix A-3 reports that the baseline transition rate to the absorbing censoring state $a$ is, if anything, increasing with unemployment duration. This negative duration dependence can be caused by a number of factors: loss of skills (Pissarides, 1992), stigma effects (Vishwanath, 1989; Jackman and Layard, 1991) or a hiring strategy in which workers are ranked according to unemployment duration (Lockwood, 1991; Blanchard and Diamond, 1994).

Figure 1: Estimated Baseline Hazards by Gender
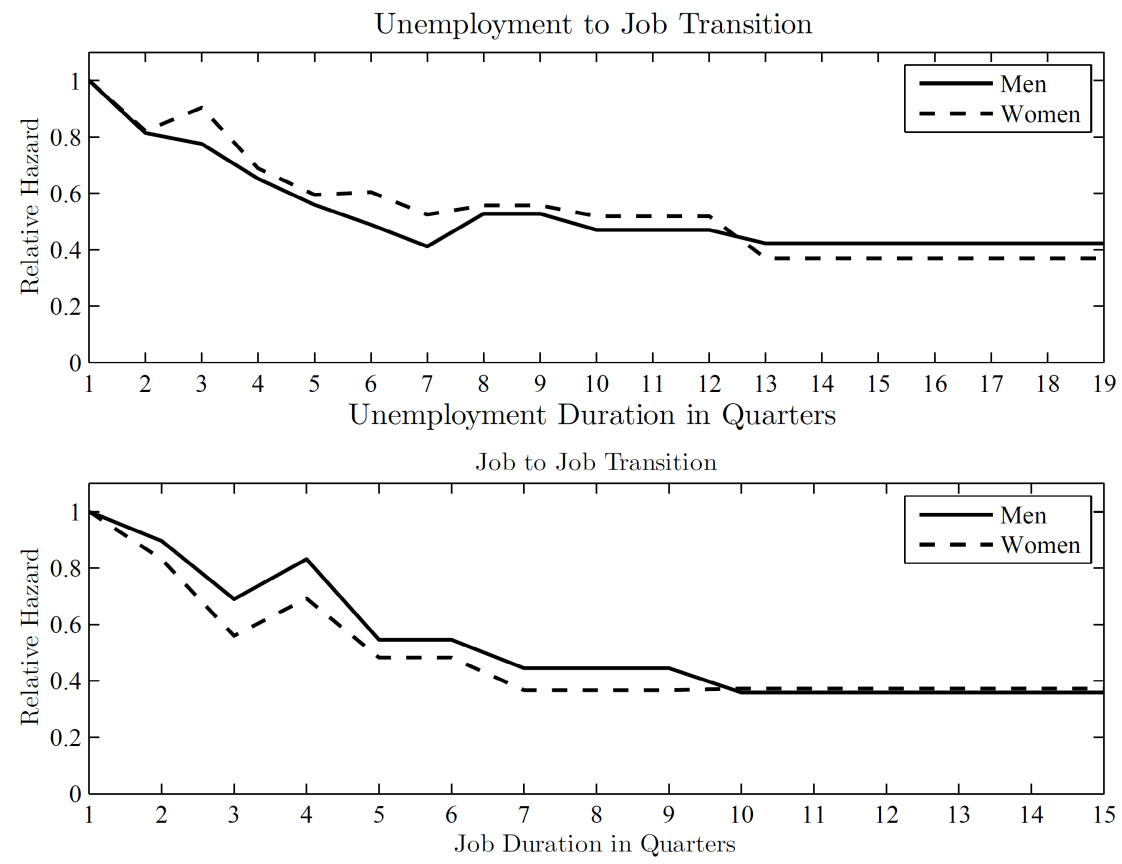

Job to Unemployment Transition

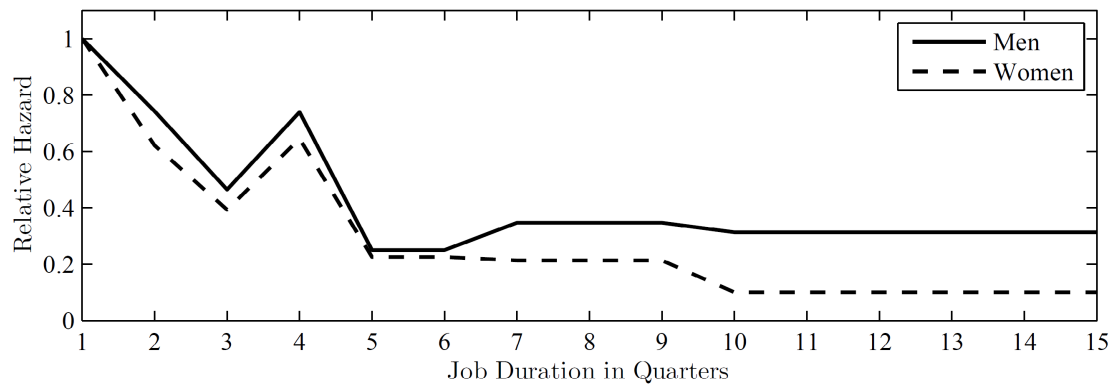

The bottom panels of Figure 1 depict the duration profiles of $(e, e)$ and $(e, u)$ tran- 
sition intensities. Both display that the job separation rate declines with tenure, a finding that is consistent with the central facts about working mobility (e.g. Topel and Ward, 1992; Farber, 1999). The spike in the fourth quarter is probably related to the non-renewal of temporary contracts. The transition rate to unemployment declines more and much faster than the job-to-job transitions. It stabilizes after 5 quarters, whereas the job-to-job transitions continue to decline gradually. This means that dismissals essentially occur during the first year, whereas job changes are spread out over a longer time span. The evidence of the spikes and of dismissals essentially occurring during the first year supports our definition of long-lasting jobs as jobs lasting one year or more.

\subsection{Lagged Occurrence and Lagged Duration Dependence}

We now discuss the influence of lagged occurrence and lagged duration dependence in details. These estimation results are reported in Table 3.

\section{Lagged Unemployment Dependence}

First, do the lagged occurrence and lagged duration of unemployment generate any scarring effect (Arulampalam et al., 2001; Gregg, 2001)? The occurrence of unemployment may indeed signal low productivity, making employers more reluctant to hire and more inclined to dismissed workers (Gibbons and Katz, 1991). ${ }^{28}$ This scarring effect may exacerbate with unemployment duration if skills depreciate progressively throughout the unemployment spell. ${ }^{29}$ In contrast, Burdett (1979) and Marimon and Zilibotti (1999) argue that a longer job search may improve the quality of the match, dissolving less rapidly as a consequence.

According to the empirical findings regarding lagged duration dependence, it is the second effect that dominates. For women, increasing the length of the previous unemployment spell by one quarter reduces the transition intensity from employment to unemployment by $3 \%$ and the job-to-job transition intensity by $4 \%$. For men, only the job-to-job transition rate falls significantly by $3 \%$ per quarter of unemployment.

Therefore, if unemployment imposes a scar, it is related to its occurrence, not to its duration. In addition, the past occurrence of unemployment imposes a scar only by raising the transition rate from employment to unemployment, not by affecting

\footnotetext{
${ }^{28}$ Given that company closures are exogenous no such inference can be made when displacement is caused by a workplace closure. However, our data do not allow to distinguish between the reasons of displacement.

${ }^{29}$ Note that the threat of benefit exhaustion may be an alternative explanation for the scarring effect of unemployment duration (Belzil, 2001; Tatsiramos, 2008), but since in Belgium benefit entitlement is indefinite, this factor is not relevant here.
} 
job-to-job transition intensities. A young man (woman) who entered a job from unemployment instead of from another job is $27 \%$ (35\%) more likely to be dismissed. ${ }^{30}$

Table 3: The Impact of the Past on Transition Intensities

\begin{tabular}{|c|c|c|c|c|c|c|}
\hline \multirow[t]{3}{*}{ Transition } & \multicolumn{2}{|c|}{$(u, e)$} & \multicolumn{2}{|c|}{$(e, e)$} & \multicolumn{2}{|c|}{$\overline{(e, u)}$} \\
\hline & (1) & (2) & (3) & (4) & $(5)$ & (6) \\
\hline & Coeff. & S.E. & Coeff. & S.E. & Coeff. & S.E. \\
\hline \multicolumn{7}{|c|}{ Men } \\
\hline Lagged unemployment duration & - & - & $-.031 * *$ & .014 & -.019 & .013 \\
\hline Previous state: unemployment & - & - & -.146 & .100 & $.237 *$ & .130 \\
\hline Lagged job duration & -.004 & .023 & -.028 & .023 & $-.127 * * *$ & .037 \\
\hline \multicolumn{7}{|c|}{ Scaling factors ${ }^{(\mathrm{a})}-$ The $\ln c_{j k}^{1} \mathrm{~s}$ are normalized to zero } \\
\hline $\ln c_{j k}^{2}$ & $.319 * * *$ & .102 & -.161 & .129 & -.005 & .142 \\
\hline $\ln c_{j k}^{3 n}$ & $.532 * * *$ & .113 & -.030 & .106 & $-.362 * * *$ & .106 \\
\hline \# of individuals & \multicolumn{2}{|c|}{6,627} & \multicolumn{2}{|l|}{ \# of spells } & \multicolumn{2}{|c|}{16,447} \\
\hline \# of parameters & \multicolumn{2}{|c|}{191} & \multicolumn{2}{|c|}{ Log-likelihood } & \multicolumn{2}{|c|}{$-41,174.1$} \\
\hline \multicolumn{7}{|c|}{ Women } \\
\hline Lagged unemployment duration & - & - & $-.041 * * *$ & .015 & $-.030 * *$ & .012 \\
\hline Previous state: unemployment & - & - & -.017 & .104 & $.302^{* *}$ & .120 \\
\hline Lagged job duration & $-.032 *$ & .019 & $-.042 * *$ & .020 & $-.063 * *$ & .029 \\
\hline \multicolumn{7}{|c|}{ Scaling factors ${ }^{(\mathrm{a})}-$ The $\ln c_{j k}^{1}$ s are normalized to zero } \\
\hline $\ln c_{j k}^{2}$ & $.560 * * *$ & .100 & -.044 & .124 & $-.251 *$ & .134 \\
\hline $\ln c_{j k}^{3}$ & $.683 * * *$ & .109 & -.109 & .101 & $-.319 * * *$ & .094 \\
\hline \# of individuals & \multicolumn{2}{|c|}{8,921} & \multicolumn{2}{|l|}{ \# of spells } & \multicolumn{2}{|c|}{20,275} \\
\hline \# of parameters & \multicolumn{2}{|c|}{197} & \multicolumn{2}{|c|}{ Log-likelihood } & \multicolumn{2}{|c|}{$-51,269.2$} \\
\hline \multicolumn{7}{|c|}{$\begin{array}{l}\text { Notes: * Significant at the } 10 \% \text { level; } * * \text { significant at the } 5 \% \text { level; *** significant at the } 1 \% \text { level. } \\
\text { (a) The scaling factors } c_{j k}^{s} \text { were introduced in Subsection } 3.1 \text {. The scaling factors } c_{j k}^{s} \text { for } s=2,3 \text { are } \\
\text { proportional shifts of the corresponding }(j, k) \text { transition intensities across subsequent spells, with the } \\
\text { first unemployment and job transition intensities as references, i.e. } c_{j k}^{1}=1 \text {. For instance, } \ln c_{u e}^{2} \text { is } \\
\text { the shift of the hiring rate after the first job with respect to the hiring rate after graduation (ln } c_{u e}^{1} \text { is } \\
\text { normalized to zero); } \ln c_{u e}^{3} \text { is the shift of the subsequent hiring rates with respect to the hiring rate } \\
\text { after graduation. }\end{array}$} \\
\hline
\end{tabular}

\section{Lagged Job Dependence}

The hiring rate increases dramatically with the order of the unemployment spell. As compared to the hiring rate in the first unemployment spell, the hiring rate in the second unemployment spell is 38\% higher for young men and even $75 \%$ higher for young women; in the third and the subsequent unemployment spells the hiring rates for men and women increase even by $70 \%$ and $98 \%$, relative to the first spell. ${ }^{31} \mathrm{We}$ regard this as evidence that, for the labour market integration of long-term unemployed youth, it is essential to acquire work experience, however short. The fact that this effect is conditional on the duration of the past work experience suggests that there

\footnotetext{
${ }^{30} 27 \approx[\exp (.237)-1] \cdot 100$ and $35 \approx[\exp (.302)-1] \cdot 100$. Note that the effect for men is only significant at $10 \%$.

${ }^{31}$ These figures are obtained from the point estimates of $\ln c_{u e}^{s}$ for $s=2,3$ reported in column (1) of Table 3 and calculated as in the previous footnote.
} 
is a signalling mechanism at work: accepting a job could signal higher productivity, through, e.g., a higher motivation to work. Even if these findings demonstrate that the first work experience dramatically facilitates the subsequent job finding, they also suggest that the positive effect of work experience may fade away as youth acquires more of it. The hiring rate increases at a decreasing rate: moving from no work experience to a first job boosts the subsequent hiring rate by more than moving from the first job to the second one.

Past work experience does not only have a strong positive impact on the hiring rate. It also reinforces tenure in the subsequent job, at least from the third spell onwards. A second job does not last significantly longer than the first one, ${ }^{32}$ but the expected duration of each subsequent job is significantly higher: even if the job-to-job transition rate is not affected, the transition rate to unemployment falls by $30 \%$ for men and by $27 \%$ for women. ${ }^{33}$

The length of the previous job may affect both the hiring rate and the duration of the subsequent job. On the one hand, the longer one has been employed in the past, the more time the worker has had to integrate in informal networks enhancing job finding (Ioannides and Loury, 2004) and to acquire transferable skills reinforcing the willingness of subsequent employers to hire and retain these workers. On the other hand, the longer a worker has been occupied by the same employer, the more specific human capital is lost at lay off. Consequently, the productivity of these workers in a new job may not match the higher reservation wage that these workers set to avoid a drop in their earnings (Ljungqvist and Sargent, 1998). This slows down the reemployment rate and stimulates on-the-job-search, reinforcing job-to-job transitions.

From Table 3 we infer that the length of the previous job does not affect the transition rate from unemployment to employment at a significance level of 5\%. In contrast, the length of the previous job increases current job duration: increasing lagged job tenure by one quarter decreases the current job-to-unemployment transition intensity by $12 \%$ for men and $6 \%$ for women. For women, but not for men, this also decreases the job-to-job transitions by $4 \%$. These findings suggest that throughout a job spell workers accumulate both specific and general skills. These factors roughly balance out in determining the speed at which a subsequent job is found. However, once the transition to a new job has been made, it is the impact related to the accumulation of general skills that dominates.

\footnotetext{
${ }^{32}$ For women it does last longer, but only at a significance level of $10 \%$. The point estimates of $\ln c_{e u}^{2}$ for men are instead equal to -0.005 and not significant.

${ }^{33}$ These figures are obtained from the point estimates of $\ln c_{e u}^{3}$ reported in column (5) of Table 3.
} 


\subsection{Summary and the Stepping Stone Hypothesis}

In a similar study on Australian youth, Doiron and Gørgens (2008) find evidence for occurrence dependence, but not for lagged duration dependence. An additional spell of employment (unemployment) increases the probability of being employed (unemployed) in the future and the size of these effects are of similar magnitude. In this study we broadly find that the direction of these lagged occurrence dependence effects are also present, but that the positive impact of past employment is larger in magnitude than that of past unemployment: an experience of unemployment in the past makes a transition to unemployment more likely, whereas the past occupation of a job both boosts the hiring rate and reduces the chances of being fired from a job.

For Belgian disadvantaged youth it is not only the occurrence of past labour market states that matters. In addition, both lagged unemployment duration and lagged job tenure modestly influence current transition intensities. This suggests that, in contrast to the Australian labour market, the time spent in labour market states plays a role. Consequently, the depreciation and accumulation of human capital during, respectively, unemployment and employment cannot be discarded as explanatory factors of the labour market transitions realized by Belgian youth.

With regard to the stepping stone hypothesis of short-lived jobs, we find contrasting forces, some supporting and some negating it. On the one hand, the pattern of lagged duration dependence negates it. By accepting a short-lived job the worker indeed forgoes the opportunity of improving the job match by extending job search: the longer one has been unemployed in the past, the more likely that the current job lasts longer.

On the other hand, the baseline transition intensity from unemployment to employment exhibits clear negative current duration dependence (see Figure 1). Consequently, by currently rejecting a short-lived job offer, the worker reduces her chances of finding a job later on. In addition and more importantly, past job experiences boost quite dramatically the job finding rate in the subsequent unemployment spells. This effect increases with the number of labour market experiences, but at a decreasing rate. This suggests that for youth the conversion rate to a long-lasting job crucially depends on the speed at which one acquires the first work experience. However, our findings also suggest that, in line with those of Gagliarducci (2005) and García Pérez and Muñoz-Bullón (2007), once this first work experience has been acquired, the stepping stone effect decreases with the number of job experiences and job interruptions. The observation period in this study is, however, too short to verify whether there exists a threshold number of work experience beyond which short-lived jobs are no longer springboards to long-lasting jobs. 


\subsection{Other Coefficients}

Finally, we briefly comment on the estimated coefficients of the other explanatory variables reported in Tables A-5 and A-7 in Internet Appendix A-3. First, the estimated coefficients of most of the observed explanatory variables are in line with expectations. The only dissonance concerns the impact of the UB. For men the level of UB has, as expected, a large and significantly negative impact on the transition rate from unemployment to employment. However, for women this impact is large and significantly positive. To understand this, we need to recall our discussion in Section 2, where we explained that this coefficient is only identified on the basis of those young workers who have acquired a sufficiently long (more than one year) work experience during the observation period. A second point is that the empirical analysis does not control for the wages earned by these workers. Since the level of UB is (within a range) proportional to past wages, a higher level of UB may also reflect a higher past wage and, consequently, a higher productivity. This may explain the counterintuitive finding for women. With regards to the anticipation effect of the drop in the UB level, we do not find clear evidence in line with the theory, but this can be due to the fact that these effects are identified on a relatively small population: the coefficients are unstable and measured with little precision.

Second, the estimated probability masses and the location of each mass point suggest an important diversity in the impact of unobserved characteristics on the transition intensities. The discrete distribution function of the random variable $\mathbf{v}$ is found to have 4 probability masses for men and 5 for women.

\section{Simulations}

The parameter estimates discussed in the previous section did not allow us to formulate a definite conclusion on our main research question: are short-lived jobs stepping stones to long-lived jobs? In this section we provide an answer and a quantification of the effect on the basis of simulations. The reliability of these simulations crucially depends on the capacity of our event history model to predict the realized labour market transition of the individuals retained in the sample. That is why, in a first step, we check the goodness-of-fit of our model. In a second step, we will formulate more precisely the object of evaluation. Finally, we present the simulation results regarding the central research question of this study.

\subsection{Goodness-of-Fit}

To construct goodness-of-fit statistics of the model, we use the parameter estimates to simulate 999 labour market histories for each individual in the sample. Replicating 
the simulation 999 times allows us to construct empirical 95\% confidence intervals on the empirical distribution of the duration in each labour market state ( $u$ or $e$ ) and of the transitions to the possible destination states $(u, e$ or $a)$. The goodness-of-fit can then easily be checked by verifying whether the observed frequencies lie within the confidence intervals of the simulated ones.

As a consequence of stock sampling and time-varying explanatory variables, which can be state specific, such as the firm characteristics, the simulation involves a number of complications. In Internet Appendix A-2 we discuss how these complications are addressed and list the steps involved in the simulation procedure.

The first panel of Table 4 contrasts the actual unemployment and job duration frequencies with the simulated counterparts and reports simulated confidence intervals. The model fits very well the observed frequencies of the duration distributions, in particular for women. For men, the model tends to slightly overpredict short unemployment spells and slightly underpredict long ones.

The second panel of Table 4 reports the fit with respect to the destination states. The model performs less, but still reasonably well, in predicting the fractions entering a particular destination state. The job-to-job transitions are somewhat overpredicted and job-to-unemployment transitions underpredicted, but again the size of the misalignment is not so large.

Finally, the third panel of Table 4 clarifies that the model performs extremely well in predicting, for those individuals who undertook a short-lived job as a way out of the first unemployment spell, the probabilities of finding a long-lasting job within 2 to 8 quarters after the short-lived job. In other words, the model perfectly fits those statistics which the evaluation analysis of the next subsections is based on.

\subsection{The Object of Evaluation}

The central question of this paper is whether a short-lived job might be a stepping stone to more job security or, in contrast, trap young disadvantaged workers in a cycle between dead-end jobs and unemployment. A short-lived job is defined as a job lasting at most one quarter and involuntarily ending in unemployment. ${ }^{34}$ As explained in the Introduction, we exclude longer spells and jobs ending by a transition to another job as to provide a lower bound to the stepping stone effect of a short-term job. Job security is attained if a worker enters a long-lasting job enduring at least four quarters.

One may argue that the measure of job security is arbitrary. We justify this choice by the observation that the bulk of the dismissals occurs during the first year (see Figure 1). Nevertheless, we agree that some sensitivity analysis with regards this threshold makes sense. Since the exit rate from a job exhibits a peak in the fourth quarter, we test whether our findings are sensitive to setting the threshold at 5 quarters.

\footnotetext{
${ }^{34} \mathrm{We}$ identify the interruption of the job as involuntary when the job ends in (insured) unemployment.
} 
Table 4: Simulated and Actual Distributions of Durations and Transitions

\begin{tabular}{|c|c|c|c|c|c|c|c|c|}
\hline \multirow{3}{*}{ Quarters } & \multicolumn{4}{|c|}{ Men } & \multicolumn{4}{|c|}{ Women } \\
\hline & \multirow{2}{*}{$\begin{array}{c}\text { Actual } \\
\text { frequency }\end{array}$} & \multirow[t]{2}{*}{$\begin{array}{l}\text { Simulated } \\
\text { frequency }\end{array}$} & \multicolumn{2}{|c|}{$\begin{array}{l}95 \% \text { confidence } \\
\text { interval }\end{array}$} & \multirow{2}{*}{$\begin{array}{c}\text { Actual } \\
\text { frequency } \\
\text { ent duration }\end{array}$} & \multirow[t]{2}{*}{$\begin{array}{l}\text { Simulated } \\
\text { frequency }\end{array}$} & \multicolumn{2}{|c|}{$\begin{array}{l}95 \% \text { confidence } \\
\text { interval }\end{array}$} \\
\hline & & & & employm & & & & \\
\hline 1 & .110 & .129 & .113 & .144 & .111 & .108 & .098 & .119 \\
\hline 2 & .052 & .054 & .046 & .062 & .048 & .047 & .041 & .053 \\
\hline 3 & .033 & .028 & .023 & .035 & .030 & .029 & .024 & .034 \\
\hline 4 & .126 & .138 & .128 & .148 & .120 & .125 & .116 & .134 \\
\hline 5 & .178 & .182 & .171 & .194 & .166 & .169 & .159 & .179 \\
\hline 6 & .115 & .113 & .104 & .123 & .111 & .113 & .105 & .123 \\
\hline 7 & .075 & .071 & .064 & .079 & .077 & .077 & .070 & .084 \\
\hline $8-9$ & 109 & .104 & .095 & .114 & .107 & .106 & .098 & .114 \\
\hline $10-12$ & .087 & .081 & .073 & .089 & .090 & .090 & .083 & .097 \\
\hline \multirow[t]{2}{*}{$13-19$} & .116 & .099 & .089 & .110 & .140 & .137 & .126 & .146 \\
\hline & \multicolumn{8}{|c|}{ Job tenure } \\
\hline 1 & .384 & .394 & .369 & .421 & .374 & .384 & .366 & .401 \\
\hline 2 & .169 & .178 & .165 & .190 & .166 & .166 & .155 & .178 \\
\hline 3 & .095 & .096 & .086 & .105 & .095 & .094 & .085 & .103 \\
\hline 4 & .086 & .086 & .076 & .095 & .091 & .087 & .079 & .095 \\
\hline $5-6$ & .081 & .079 & .070 & .088 & .087 & .084 & .076 & .092 \\
\hline $7-9$ & .094 & .083 & .074 & .093 & .090 & .088 & .080 & .096 \\
\hline $10-15$ & .090 & .086 & .072 & .100 & .097 & .097 & .088 & .107 \\
\hline Transitions & \multicolumn{8}{|c|}{ Transitions from unemployment } \\
\hline$(u, e)$ & .595 & .629 & .594 & .654 & .524 & .518 & .499 & .535 \\
\hline$(u, a)$ & .302 & .296 & .272 & .336 & .371 & .377 & .361 & .399 \\
\hline Right cens. & .103 & .075 & .066 & .086 & .106 & .105 & .096 & .113 \\
\hline & \multicolumn{8}{|c|}{ Transitions from employment } \\
\hline$(e, e)$ & .282 & .346 & .315 & .385 & .276 & .301 & .282 & .321 \\
\hline$(e, u)$ & .319 & .279 & .255 & .304 & .335 & .332 & .312 & .352 \\
\hline$(e, a)$ & .150 & .146 & .128 & .166 & .134 & .133 & .116 & .148 \\
\hline Right cens. & 249 & .228 & .206 & .249 & .256 & .235 & .222 & .248 \\
\hline $\begin{array}{l}\text { Time elapsed since } \\
\text { short-lived job }\end{array}$ & \multicolumn{8}{|c|}{ Probability of having found a long-lasting job after a short-lived job ${ }^{(a)}$} \\
\hline 2 quarters & .114 & .119 & .099 & .139 & .140 & .140 & .123 & .161 \\
\hline 3 quarters & .197 & .214 & .186 & .241 & .211 & .234 & .212 & .266 \\
\hline 4 quarters & 269 & 299 & .268 & .334 & .299 & .328 & 298 & .363 \\
\hline 5 quarters & .374 & .377 & .336 & .415 & .387 & .401 & .369 & .438 \\
\hline 6 quarters & .452 & .445 & .398 & .480 & .455 & .466 & .430 & .503 \\
\hline 7 quarters & .497 & .502 & .453 & .538 & .539 & .520 & .483 & .558 \\
\hline 8 quarters & .536 & .551 & .494 & .592 & .589 & .567 & .527 & .604 \\
\hline
\end{tabular}


We conclude that this hardly affects the findings. ${ }^{35}$ Further sensitivity analysis in which the threshold is set much higher is not feasible with the available data. This requires a longer observation period.

Formally, we are interested in the causal impact of a binary treatment, being hired in a short-lived job, that is assigned in some quarter $s \in N_{0} \equiv\{1,2, \ldots\}$ during the first unemployment spell experienced after leaving school or not assigned at all, which is represented as a treatment at infinity $(s=\infty) .{ }^{36}$ The latter treatment corresponds to a strategy in which one rejects all the short-lived jobs as a way out of the first unemployment spell. The set of mutually exclusive treatments can thus be denoted by $\bar{N}_{0} \equiv N_{0} \cup\{\infty\}$. In principle, the outcome variable of interest is the potential duration $T_{l}^{*}(s) \in N_{0}$ from graduation until entry in a long-lasting job that would realize if the treatment is assigned in quarter $s$. The actual treatment is assigned according to a $\bar{N}_{0^{-}}$ valued random variable $S$ and the actual outcome is $T_{l} \equiv T_{l}^{*}(S)$; all other outcomes are counterfactual.

Now consider a sample of individuals $i$ with $i=1,2, \ldots I$ and assume that we observe for each of these individuals $j=1,2, \ldots J$ labour market histories. In the data we observe only one labour market history $(J=1)$ for each individual. However, in the simulations we can construct a large number of labour market histories for any given individual, since these are identified in the model through the given time profile of the observed individual characteristics together with a given draw from the of unobserved heterogeneity distribution associated to an individual. As shown below, this allows us to simulate average treatment effects at the individual level and, consequently, the distribution of the treatment effect. ${ }^{37}$

The realized potential outcomes and treatments for a particular labour market history $j$ associated to individual $i$ can then be denoted by $T_{l i j} \equiv T_{l i j}^{*}\left(S_{i j}\right)$ and $S_{i j}$, respectively. All other outcomes are counterfactual, in particular the counterfactual of interest $T_{l i j}^{*}(\infty)$, the duration to a long-lasting job if all short-lived jobs would be rejected. With this notation, the average individual treatment effect of the treated (AITT) is defined as

$$
\Delta_{i}(s)=E_{j}\left[T_{l i j}^{*}\left(S_{i j}\right)-T_{l i j}^{*}(\infty) \mid S_{i j}<\infty\right] \text {, for } i=1, \ldots, I,
$$

where the conditional expectation is taken over the $J$ simulated labour market histories of each sampled individual $i$ who is eventually treated $\left(S_{i j}<\infty\right)$.

In practice, this AITT cannot be identified, since it requires an observation window of infinite length. The observation window is limited by two forms of censoring. First, there is the exogenous censoring induced by the data gathering. We start observing

\footnotetext{
${ }^{35}$ See panel (b) of Table A-9 in Internet Appendix A-3.

${ }^{36}$ The notation in this section is inspired by the one in Abbring and van den Berg (2003b).

${ }^{37}$ Note however that the treatment effect depends on observables and unobservables which enter the labour market transition intensities in a proportional fashion.
} 
the school-leavers without any work experience only from their fourth quarter of unemployment onwards. In addition, the labour market trajectory is right censored at the end of 2001, after maximum 16 quarters. Second, there is the endogenous censoring in the absorbing state $a$ imposed on the econometric model for technical reasons.

In order to face these censoring problems, we propose an alternative outcome variable and we alter the conditioning set of the AITT. We will label this new statistic the conditional average individual treatment effect of the treated (CAITT). The new counterfactual outcome variable is a binary indicator equal to one if an individual finds a long-lasting job within $d$ quarters from the moment $s$ at which (s)he is assigned to the treatment and zero otherwise $:^{38}$

$$
Y_{d}^{*}(s)=\mathbb{1}\left(T_{l}^{*} \leq s+d\right) .
$$

If we denote by $T_{a}^{*}(s)$ the counterfactual duration, realized if the treatment is assigned in quarter $s$, from graduation to entry in the endogenous censoring state $a$, we can define a counterfactual censoring indicator $C_{d}(s)$ as

$$
C_{d}^{*}(s)=\mathbb{1}\left[T_{a}^{*}(s) \leq \min \left(T_{l}^{*}(s), s+d\right)\right] .
$$

There is no censoring if state $a$ is entered after being hired in a long-lasting job or more than $d$ quarters after entering a short-lived job.

The CAITT is then defined as

$$
\tilde{\Delta}_{d i}(m)=E_{j}\left[Y_{d i j}^{*}\left(S_{i j}\right)-Y_{d i j}^{*}(\infty) \mid C_{d i j}^{*}\left(S_{i j}\right)=0,5 \leq S_{i j} \leq m\right],
$$

for $d=1, \ldots, D, i=1, \ldots, I$. In words, the CAITT measures the increase in percentage points of individual $i$ 's probability of finding a long-lasting job within $d$ quarters after entering a short-lived job compared to the counterfactual in which all short-lived jobs are rejected. In order to cope with the censoring problem, the CAITT is conditional on not being endogenously censored yet in the evaluation period and on having entered a short-lived job between the start of the observation window (4 quarters after graduation) and $m$ quarters after graduation. $m$ and $D$ are chosen such that their sum does not exceed 15 , the width of the observation window (16) reduced by the length of the long-lasting job (4) and augmented by 3 to take into account that $m$ is measured from graduation and not from the start of the observation period. In the baseline simulation we set $m=7$ and $D=8 .{ }^{39}$ Observe that the CAITT and the AITT are related in the following way: if one sums the CAITT over $d$ from one to infinity in the absence of censoring, then one obtains the AITT. Finally, note that from each CAITT we can

\footnotetext{
${ }^{38}$ In other words, $d$ is the time elapsed since treatment at which the evaluation is carried out.

${ }^{39}$ In a sensitivity analysis reported in panel (a) of Table A-9 (Internet Appendix A-3), we set $m=11$ and $D=4$. Very similar results as in the baseline simulation are obtained.
} 
also estimate a CATT by averaging the CAITTs over the retained treated population: $\tilde{\Delta}_{d}(m)=E_{i}\left[\tilde{\Delta}_{d i}(m)\right]$.

\subsection{The Simulation Results}

The simulation procedure is described in Internet Appendix A-2. Table 5 reports means and selected percentiles of the CAITT distributions for $m=7$ and $d=2,4,8$. These results show that, in very short-run, short-lived jobs are not stepping stones. Half a year after the transition to a short-lived job, the probability of having entered a long-lasting job is 1 percentage point (but not significantly) lower than if one would have rejected the short-lived job. However, after one year the stepping stone effect clearly emerges: the CATT is 5.2 percentage points for both men and women. After two years the CATT increases further to (9.5) 13.4 percentage points for (wo)men. Apparently, the stepping stone effect is more present among men than women.

Even if there is a clear stepping stone effect of short-lived jobs, the simulations also demonstrate (see Table 5 or Figure 2) that there is substantial heterogeneity in the treatment effect. The CAITT distributions reveal that, even if the CAITTs are positive for the majority of the treated population, for roughly $40 \%$ of the treated the transition to a short-lived job decreased the likelihood of entering a long-lasting job. We can also deduce from the figures that the fraction of the population that benefits from the treatment remains roughly constant with the elapsed duration $d$ since the start of the treatment. The average effect increases with $d$ because the size of the negative CAITTs decreases and the size of the positive CAITTs increases.

In order to understand the possible sources of heterogeneity in the treatment effect, we performed an OLS regression of the CAITTs on the observed and unobserved characteristics fixed at the beginning of the observation period. ${ }^{40}$ We find that the stepping stone effect is less important for youth with higher education, living in Flanders and in districts with a lower unemployment rate. We also tried to identify subpopulations for whom short-lived jobs are not stepping stones on average. However, we could not identify such a population on the basis of any combination of observed characteristics.

These results are in line with other European studies which generally find that short-term jobs are stepping stones to permanent jobs. We believe, however, that our findings are even stronger, since we find evidence of a stepping stone effect even for unsuccessful jobs involuntarily ending in unemployment after maximum one quarter. This claim is confirmed in a sensitivity analysis in which we include, in the group of the treated, also workers who make a job-to-job transition at the end of a job last-

\footnotetext{
${ }^{40}$ The estimation results with $\tilde{\Delta}_{8 i}(7)$ as dependent variable are reported in Table A-10 in Internet Appendix A-3. Even if almost all the coefficients are highly significant, their order of magnitude is small.
} 
Table 5: Simulated CAITT Distributions for $m=7$ and $d=$ $2,4,8$

\begin{tabular}{|c|c|c|c|c|c|c|c|c|c|}
\hline \multirow{4}{*}{$\begin{array}{l}\text { Statistics } \\
\text { CATT }\end{array}$} & \multicolumn{3}{|c|}{ Distribution of $\tilde{\Delta}_{2 i}(7)$} & \multicolumn{3}{|c|}{ Distribution of $\tilde{\Delta}_{4 i}(7)$} & \multicolumn{3}{|c|}{ Distribution of $\tilde{\Delta}_{8 i}(7)$} \\
\hline & \multirow[t]{2}{*}{ Mean } & \multicolumn{2}{|c|}{$95 \%$ conf int } & \multirow[t]{2}{*}{ Mean } & \multicolumn{2}{|c|}{$95 \%$ conf int } & \multirow{3}{*}{$\begin{array}{r}\text { Mean } \\
.134 \\
(.551)\end{array}$} & \multicolumn{2}{|c|}{$95 \%$ conf int } \\
\hline & & & & & Men & & & & \\
\hline & $\begin{array}{r}-.011 \\
(119 .)\end{array}$ & -.036 & .016 & $\begin{array}{r}.052 \\
(.299)\end{array}$ & .019 & .084 & & .072 & .186 \\
\hline \multicolumn{10}{|c|}{ Selected percentiles of the CAITT distributions } \\
\hline Minimum & -.587 & -.700 & -.490 & -.464 & -.580 & -.380 & -.348 & -.480 & -.260 \\
\hline 5 th & -.386 & -.445 & -.330 & -.288 & -.334 & -.240 & -.188 & -.231 & -.150 \\
\hline 10th & -.317 & -.370 & -.260 & -.237 & -.280 & -.190 & -.143 & -.180 & -.101 \\
\hline 25 th & -.169 & -.243 & .000 & -.140 & -.180 & -.092 & -.067 & -.100 & -.020 \\
\hline 50th & .048 & .030 & .070 & .027 & -.030 & .070 & .032 & -.010 & .070 \\
\hline 75th & .123 & .100 & .150 & .223 & .180 & .280 & .215 & .140 & .290 \\
\hline 90th & .195 & .170 & .240 & .389 & .340 & .444 & .504 & .376 & .622 \\
\hline 95th & .243 & .210 & .290 & .471 & .414 & .538 & .666 & .560 & .770 \\
\hline Maximum & .429 & .320 & .550 & .719 & .600 & .830 & .909 & .810 & .980 \\
\hline \# obs ${ }^{(\mathrm{a})}$ & \multicolumn{3}{|c|}{384.5} & \multicolumn{3}{|c|}{332.4} & \multicolumn{3}{|c|}{261.0} \\
\hline \multirow[b]{2}{*}{ CATT } & \multicolumn{6}{|c|}{ Women } & & & \\
\hline & $\begin{array}{r}-.010 \\
(.140)\end{array}$ & -.036 & .014 & $\begin{array}{r}.052 \\
(.328)\end{array}$ & .020 & .085 & $\begin{array}{r}.095 \\
(.567)\end{array}$ & .063 & .142 \\
\hline \multicolumn{10}{|c|}{ Selected percentiles of the CAITT distributions } \\
\hline Minimum & -.583 & -.680 & -.490 & -.489 & -.610 & -.400 & -.396 & -.530 & -.300 \\
\hline 5 th & -.398 & -.350 & -.440 & -.289 & -.340 & -.249 & -.199 & -.246 & -.150 \\
\hline 10th & -.328 & -.370 & -.270 & -.234 & -.270 & -.200 & -.147 & -.200 & -.110 \\
\hline 25th & -.170 & -.240 & -.103 & -.138 & -.180 & -.100 & -.069 & -.100 & -.040 \\
\hline 50th & .033 & .020 & .050 & .028 & -.020 & .060 & .021 & -.010 & .060 \\
\hline 75th & .129 & .100 & .160 & .203 & .155 & .268 & .187 & .140 & .250 \\
\hline 90th & .224 & .190 & .260 & .419 & .376 & .472 & .497 & .374 & .640 \\
\hline 95 th & .285 & .250 & .339 & .509 & .447 & .563 & .670 & .586 & .749 \\
\hline Maximum & .507 & .370 & .840 & .724 & .640 & .890 & .913 & .840 & .970 \\
\hline$\# \mathrm{obs}^{(\mathrm{a})}$ & & 501.7 & & & 425.6 & & & 330.4 & \\
\hline \multicolumn{10}{|c|}{$\begin{array}{l}\text { Notes: In parentheses we report the average probability of having entered a long-lasting job } \\
d \text { quarters after a short-lived job, conditional on not being endogenously censored yet in the } \\
\text { evaluation period and on having entered a short-lived job between the start of the observation } \\
\text { window ( } 4 \text { quarters after graduation) and } m \text { quarters after graduation. Formally, it is the } \\
\text { empirical counterpart of } E_{i}\left\{E_{j}\left[Y_{d i j}^{*}\left(S_{i j}\right) \mid C_{d i j}^{*}\left(S_{i j}\right)=0,5 \leq S_{i j} \leq 7\right]\right\} \text {. } \\
\text { (a) It indicates the average number of individuals satisfying the conditioning set in (9), i.e. the } \\
\text { average number of treated individuals. }\end{array}$} \\
\hline
\end{tabular}


Figure 2: Simulated CAITT Distributions for $m=7$ and $d=2,4,8$
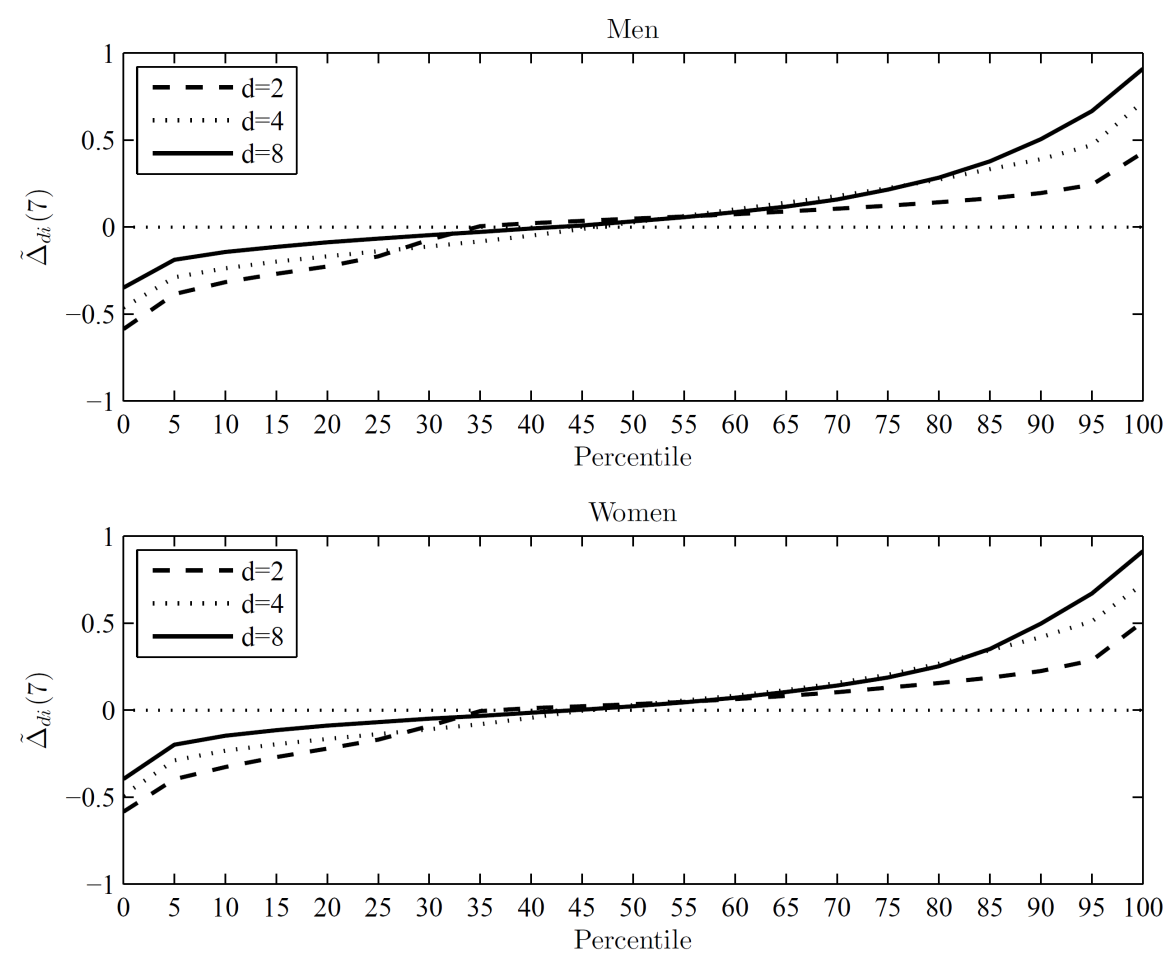

ing maximum one quarter. ${ }^{41}$ Two years after the start of the treatment, the CATT increases to (13.6) 19.3 percentage points for (wo)men an increase by more than $40 \%$ as compared to the benchmark treatment definition. ${ }^{42}$

Finally, up to now we only considered the treatment effect on the treated. It is likely that providing a short-lived job to individuals who would otherwise have not accepted such a job might generate a lower stepping stone effect: these individuals might have rejected short-lived jobs because they knew they would be harmed by accepting such jobs. We cannot however directly check this hypothesis, since we do not observe whether workers have rejected such jobs: workers who did not accept a short-lived job may have never received an offer. However, if this hypothesis is correct, we should find that imposing the treatment on those who are not treated should

\footnotetext{
${ }^{41}$ In other words, the treated are now those that exit the post-school unemployment event through a job lasting maximum one quarter, independently on whether this job ends in unemployment or in another job.

${ }^{42}$ By looking at Table 3, one can understand which factor reinforces the stepping stone effect. It was indeed found that a jobs that starts from a another job is longer-lasting than a comparable job that starts from unemployment. For more details about the CAITT distributions under this different definition of treatment, see Table A-11 and Figure A-3 in Internet Appendix A-3.
} 
reduce the stepping stone effect. This is confirmed by a simulation in which we impose a job lasting one quarter (ending in a job-to-job transition or in unemployment) on all the individuals who are still unemployed after one year since graduation. Two years after this imposed job, the probability of having entered a long-lasting job increases by (7) 17 percentage points for (wo)men. ${ }^{43}$ As compared to the simulations in which no such jobs are imposed, the reduction of the treatment effect is especially important for women, since it is nearly halved. The reader should be careful in not interpreting these last findings as the expected impact of a policy in which all long-term unemployed workers would be offered a short-lived job. The reason is that such a large scale policy would presumably generate general equilibrium effects, which cannot be captured by our model. For instance, if the stepping stone effect is generated by signaling, then this policy would make the signal less reliable, meaning that employers may no longer use it in their hiring decisions.

\section{Conclusions}

Can short-lived jobs (lasting less than one quarter and involuntarily ending in unemployment) be stepping stones to long-lasting jobs (lasting more than one year) for disadvantaged youth? This was the central question of this research. To answer this question the analysis proceeded in two steps. In a first step, a dynamic multi-state multi-spell model of labour market trajectories of Belgian long-term unemployed school-leavers was estimated using administrative data gathered between 1998 and 2001. On the basis of the estimation results of this model and by way of simulations, in a second step we carried out an a posteriori analysis. It quantifies the effect of accepting short-lived jobs as a way out of the post-school unemployment event, as opposed to rejecting them and waiting for a better job.

The model in the first step provides evidence on the presence of lagged occurrence and lagged duration dependence in the labour market experience of Belgian disadvantaged youth. This issue has hardly been investigated in the past. In a study on Australian youth Doiron and Gørgens (2008) find evidence for lagged occurrence dependence, but not for lagged duration dependence. In contrast, we find evidence for both lagged occurrence and lagged duration dependence. In addition, we find for Belgian youth a positive impact of the occurrence of past employment on subsequent employment which is larger than that of past unemployment on subsequent unemployment. For Australian youth these impacts were broadly the same. This implies that for Belgian youth there are more long lasting positive impacts from employment, irrespective of its duration, than there are negative impacts from unemployment. These factors, amongst others, support the stepping stone hypothesis. Nevertheless, we find some

\footnotetext{
${ }^{43}$ For more details, see Table A-12 and Figure A-4 in Internet Appendix A-3.
} 
evidence against the stepping stone hypothesis. The pattern of lagged duration dependence suggests that it could not be a good idea to accept a job too quickly, since delaying exit from unemployment may improve the stability of the post-unemployment job (Marimon and Zilibotti, 1999).

The simulation results reveal that the factors in favour of the stepping stone hypothesis dominate. By accepting short-lived jobs, rather than rejecting them as a way out of the first unemployment spell after graduation, the probability of entering a longlasting job is, within two years, enhanced by (9.5) 13.4 percentage points for (wo)men. Moreover, we claim that this effect is a lower bound, since we restricted the analysis to very short-lived jobs (lasting no longer than one quarter) that are unsuccessful in that they involuntarily end in unemployment rather than in another job. On the other hand, the simulations indicate that there is substantial heterogeneity in the effect. Roughly, 40 percent of those who accepted short-lived jobs would have speeded up their labour market integration by rejecting those jobs. The stepping stone effect was found to be smaller for certain subpopulations: the higher educated youth, those living in Flanders and in districts with low unemployment rates. However, we were not able to identify, on the basis of observed characteristics, any subpopulation for which short-lived jobs prove to be dead-end jobs on average.

These findings need to be qualified for a number of reasons. First, the strategy of accepting short-lived jobs may have less beneficial long-run consequences on other dimensions of the quality of a job, such as on the level of wages. Second, as mentioned in Subsection 4.2, our findings also suggest, in line with those of Gagliarducci (2005) and García Pérez and Muñoz-Bullón (2007), that, once a first work experience has been acquired, the stepping stone effect may be less important or even disappear. Thirdly, in our simulation we estimated the treatment effect on the treated. This stepping stone effect cannot be extrapolated from the non-treated population. As a matter of fact, those who rejected short-lived jobs may have done so because they knew they would be harmed. In a sensitivity analysis in which we imposed a short-lived job on all long-term unemployed youth, we indeed find a smaller stepping stone effect than the one on the treated population only, especially for women. Finally, if the stepping stone effect is generated by signaling higher productivity or motivation, which is likely if we restrict our attention to short-term employment, ${ }^{44}$ then policies stimulating the transition to short-term jobs might not generate the positive effects we report here. By doing so, the signal may indeed become less reliable, meaning that employers may no longer use it in their hiring decisions.

\footnotetext{
${ }^{44}$ Other mechanisms, such as those related to the accumulation of human capital, take more time.
} 


\section{Appendix}

\section{A-1 Deriving the Likelihood Function}

In this appendix we specify the contribution to the likelihood function of a completed spell $s$ whose origin state is $j$. Suppose that after a sojourn of $t_{s}$ quarters in the origin state $j$, a transition to the destination state $k$ is observed, with $(j, k) \in \mathscr{Z}$. Denote $D_{j k}$ an indicator variable equal to 1 if a $(j, k)$ transition is observed and 0 otherwise. We now suppress the set of observed and unobserved characteristics, but in what follows we are implicitly conditioning on them.

The contribution to the likelihood function is the unconditional probability of jointly observing the departure from $j$ and the transition to $k$ after a sojourn of $t_{s}$ quarters in the origin state $j$, i.e. $\operatorname{Pr}\left(t_{s}-1 \leq T_{j}<t_{s}, D_{j k}=1\right)$. Since we have quarterly information, we do not exactly know when the transition occurs within two consecutive quarters and the best that can be done is to model the probability of observing the departure within two consecutive quarters. This probability can be rewritten as

$$
\operatorname{Pr}\left(T_{j} \geq t_{s}-1\right) \operatorname{Pr}\left(t_{s}-1 \leq T_{j}<t_{s}, D_{j k}=1 \mid T_{j} \geq t_{s}-1\right)
$$

which is the product of the survivor function and of a conditional probability.

The survivor function in state $j$ for $t_{s}-1$ quarters is given by

$$
\begin{aligned}
\operatorname{Pr}\left(T_{j} \geq t_{s}-1\right) & =\exp \left\{-\int_{0}^{t_{s}-1} \sum_{(j, k) \in \mathscr{J}} \theta_{j k}^{s}(\tau) d \tau\right\} \\
& =\exp \left\{-\int_{0}^{1} \sum_{(j, k) \in \mathscr{J}} \theta_{j k}^{s}(\tau) d \tau-\int_{1_{(j, k) \in \mathscr{J}}^{2}} \theta_{j k}^{s}(\tau) d \tau-\ldots-\int_{t_{s}-2}^{t_{s}-1} \sum_{(j, k) \in \mathscr{J}} \theta_{j k}^{s}(\tau) d \tau\right\},
\end{aligned}
$$

where $\mathscr{J}=\mathscr{E}$ if $j=e$ and $\mathscr{J}=\mathscr{U}$ if $j=u$. We assume now that the transition intensities are constant within two consecutive quarters, since we do not have information on what happens within each interval. Under this assumption, we can specify the discrete time process as a continuous time model and the hazard functions can be taken out of the integrals, yielding

$$
\begin{aligned}
\operatorname{Pr}\left(T_{j} \geq t_{s}-1\right) & =\exp \left\{-\sum_{\tau=1}^{t_{s}-1} \sum_{(j, k) \in \mathscr{J}} \theta_{j k}^{s}(\tau)\right\} \\
& =\prod_{\tau=1}^{t_{s}-1} \exp \left\{-\sum_{(j, k) \in \mathscr{J}} \theta_{j k}^{s}(\tau)\right\} \equiv S_{j}\left(t_{s}-1\right)
\end{aligned}
$$


The conditional probability in (A-1) can be written as

$$
\begin{aligned}
& \operatorname{Pr}\left(t_{s}-1 \leq T_{j}<t_{s}, D_{j k}=1 \mid T_{j} \geq t_{s}-1\right) \\
& =\frac{\int_{t_{s}-1}^{t_{s}} \theta_{j k}^{s}(\tau) \exp \left\{-\int_{0}^{\tau} \sum_{(j, k) \in \mathscr{J}} \theta_{j k}^{s}(r) d r\right\} d \tau}{\exp \left\{-\int_{0}^{t_{s}-1} \sum_{(j, k) \in \mathscr{J}} \theta_{j k}^{s}(r) d r\right\}}
\end{aligned}
$$

and exploiting again the assumption that the transition intensities are constant within two consecutive quarters, equation (A-3) can be rewritten, following Cockx (1997), as

$$
\left[1-\exp \left\{-\sum_{(j, k) \in \mathscr{J}} \theta_{j k}^{s}\left(t_{s}\right)\right\}\right] \times \frac{\theta_{j k}^{s}\left(t_{s}\right)}{\sum_{(b, c) \in \mathscr{J}} \theta_{b c}^{s}\left(t_{s}\right)} .
$$

Multiplying (A-2) by (A-4) and reintroducing the set of observed and observed characteristics yield equation (3), which is the contribution to the likelihood function of a complete spell $s$ for $j \in\{u, e\}$.

\section{References}

Abbring, J.H., and G.J. van den Berg (2003a) 'The identifiability of the mixed proportional hazards competing risks model.' Journal of the Royal Statistical Society Series B 65(3), 701-710

_ (2003b) 'The nonparametric identification of treatment effects in duration models.' Econometrica 71(5), 1491-1517

Addison, J.T., and C.J. Surfield (2006) 'Does atypical work help the jobless? evidence from a caeas/cps cohort analysis.' IZA discussion paper No. 2325, Bonn

Amuedo-Dorantes, C., M.A. Malo, and F. Muñoz-Bullón (2006) 'The role of temporary help agencies in facilitating temp-to-perm transitions.' IZA discussion paper No. 2177, Bonn

Andersson, F., H. Holzer, and J. Lane (2007) 'Temporary help agencies and the advancement prospects of low earners.' IZA discussion paper No. 3113, Bonn

Arulampalam, W., P. Gregg, and M. Gregory (2001) 'Unemployment scarring.' Economic Journal 111(475), 577-584

Autor, D.H., and S. Houseman (2005) 'Do temporary help jobs improve labor market outcomes for low-skilled workers? evidence from random assignments.' Upjohn Institute Staff Working Paper No. 05-124

Belzil, C. (2001) 'Unemployment insurance and subsequent job duration: Job matching versus unobserved heterogeneity.' Journal of Applied Econometrics 16(5), 619-636

Berton, F., F. Devicienti, and L. Pacelli (2007) 'Temporary jobs: Port of entry, trap, or just unobserved heterogeneity?' Working paper No. 68, LABOR, Collegio Carlo Alberto 
Bhargava, A. (1991) 'Identification and panel data models with endogenous regressors.' Review of Economic Studies 58(1), 129-140

Blanchard, O.J., and P. Diamond (1994) 'Ranking, unemployment duration, and wages.' Review of Economic Studies 61(3), 417-434

Booth, A.L., M. Francesconi, and J. Frank (2002) 'Temporary jobs: Stepping stones or dead ends?' Economic Journal 112(480), F189-F213

Brinch, C.N. (2007) 'Nonparametric identification of the mixed hazards model with time-varying covariates.' Econometric Theory 23(2), 349-354

Burdett, K. (1979) 'Unemployment insurance payments as a search subsidy: A theoretical analysis.' Economic Inquiry 42(3), 333-343

Casquel, E., and A. Cunyat (2008) 'Temporary contracts, employment protection and skill: A simple model.' Economics Letters 100(3), 333-336

Cockx, B. (1997) 'Analysis of transition data by the minimum chi-square method: An application to the welfare spells in belgium.' Review of Economics and Statistics 79(3), 392-405

Cockx, B., and M. Dejemeppe (2005) 'Duration dependence in the exit rate out of unemployment in belgium. is it true or spurious?' Journal of Applied Econometrics 20(1), 1-23

Doiron, D., and T. Gørgens (2008) 'State dependence in youth labor market experiences, and the evaluation of policy interventions.' Journal of Econometrics 145(1), 81-97

European Commission (2001) 'Employment and social policies: A framework for investing in quality.' $\operatorname{COM}(2001) 313$ final, http://ec.europa.eu/employment_social/news/2001/sep/quality_en.pdf

Farber, H.S. (1999) 'Mobility and stability: The dynamics of job change in labor markets.' In Handbook of Labor Economics, Volume 3B, ed. O.C. Ashenfelter and D. Card (Amsterdam: Elsevier Science) chapter 37, pp. 2439-2483

Flinn, C., and J.J. Heckman (1982) 'Models for the analysis of labor force dynamics.' In Advances in Econometrics, ed. R.L. Basmann and G.F. Rhoeds JAI Press Greenwich pp. 35-95

Gagliarducci, S. (2005) 'The dynamics of repeated temporary jobs.' Labour Economics 12(4), 429-448

García Pérez, J.I., and F. Muñoz-Bullón (2007) 'Transitions into permanent employment in spain: An empirical analysis for young workers.' Business economics working paper No. wb073808, Universidad Carlos III, Departamento de Economía de la Empresa.

Gaure, S., K. Røed, and L. Westlie (2008) 'The impacts of labour market policies on job search behavior and post-unemployment job quality.' IZA discussion paper No. 3802, Bonn

Gaure, S., K. Røed, and T. Zhang (2007) 'Time and causality: A monte carlo assessment of the timingof-events approach.' Journal of Econometrics 141(2), 1159-1195

Gibbons, R., and L.F. Katz (1991) 'Layoffs and lemons.' Journal of Labor Economics 9(4), 351-380 
Göbel, C., and E. Verhofstadt (2008) 'The role of temporary employment for the integration of schoolleavers into permanent employment.' Paper presented at the XXII Annual Conference of the European Society for Population Economics, June 19-21, University College London

Gregg, P. (2001) 'The impact of youth unemployment on adult unemployment in the ncds.' Economic Journal 111(475), F626-F653

Gritz, R.M. (1993) 'The impact of training on the frequency and duration of employment.' Journal of Econometrics 57(1-3), 21-51

Hagen, T. (2003) 'Do fixed-term contracts increase the long-term employment opportunities of the unemployed?' ZEW discussion paper No. 03-49, Mannheim

Heckman, J.J. (1981) 'The incidental parameters problem and the problem of initial conditions in estimating a discrete time-discrete data stochastic process.' In Structural Analysis of Discrete Data with Econometric Applications, ed. C.F. Manski and D. McFadden (Cambridge: The MIT Press) pp. 179-195

Heckman, J.J., and B. Singer (1984) 'A method for minimizing the impact of distributional assumptions in econometric models for duration data.' Econometrica 52(2), 271-320

Heckman, J.J., J. Smith, and N. Clements (1997) 'Making the most out of programme evaluations and social experiments: Accounting for heterogeneity in programme impacts.' Review of Economic Studies 64(4), 487-535

Heinrich, C.J., P.R. Mueser, and K.R. Troske (2007) 'The role of temporary help employment in lowwage worker advancement.' NBER working paper No. 13520

Honoré, B.R. (1993) 'Identification results for duration models with multiple spells.' Review of Economic Studies 60(1), 241-246

Horny, G., and M. Picchio (2009) 'Identification of lagged duration dependence in multiple spells competing risks models.' Forthcoming Discussion Paper, Université catholique de Louvain, Département des Sciences Economiques.

Ichino, A., F. Mealli, and T. Nannicini (2008) 'From temporary help jobs to permanent employment: What can we learn from matching estimators and their sensitivity?' Journal of Applied Econometrics 23(3), 305-327

Ioannides, Y.M., and L.D. Loury (2004) 'Job information networks, neighborhood effects, and inequality.' Journal of Economic Literature 42(4), 1056-1093

Jackman, R., and R. Layard (1991) 'Does long-term unemployment reduce a person's chance of a job? a time-series test.' Economica 58(229), 93-106

Kvasnicka, M. (2008) 'Does temporary help work provide a stepping stone to regular employment?' NBER working paper No. 13843

Larsson, L., L. Lindqvist, and O. Nordström Skans (2005) 'Stepping-stones or dead-ends? an analysis of swedish replacement contracts.' IFAU working paper No. 2005:18, Uppsala 
Ljungqvist, L., and T.J. Sargent (1998) 'The european unemployment dilemma.' Journal of Political Economy 106(3), 514-550

Lockwood, B. (1991) 'Information externalities in the labour market and the duration of unemployment.' Review of Economic Studies 58(4), 733-753

Marimon, R., and F. Zilibotti (1999) 'Unemployment vs. mismatch of talents: Reconsidering unemployment benefits.' Economic Journal 109(455), 266-291

Meyer, B.D. (1990) 'Unemployment insurance and unemployment spells.' Econometrica 58(4), $757-$ 782

Mroz, T.A., and T.H. Savage (2006) 'The long-term effects of youth unemployment.' Journal of Human Resources 41(2), 259-293

OECD (1999) Employment Outlook (Paris: OECD)

_ (2004a) Benefits and Wages (Paris: OECD)

— (2004b) Employment Outlook (Paris: OECD)

_ (2007) Jobs for Youth: Belgium (Paris: OECD)

Omori, Y. (1998) 'The identifiability of independent competing risks models with multiple spells.' Oxford Bulletin of Economics and Statistics 60(1), 107-116

Picchio, M. (2008) 'Temporary contracts and transitions to stable jobs in italy.' Labour 22(2), 147-174

Pissarides, C.A. (1992) 'Loss of skill during unemployment and the persistence of employment shocks.' Quarterly Journal of Economics 107(4), 1371-1391

Ridder, G. (1984) 'The distribution of single-spell duration data.' In Studies in Labor Market Dynamics, ed. G.R. Neumann and N.C. Westergård (Darmstadt: Springer-Verlag) chapter 3, pp. 45-73

_ (1990) 'The non-parametric identification of generalized accelerated failure-time models.' Review of Economic Studies 57(2), 167-181

Tatsiramos, K. (2008) 'Unemployment insurance in europe: Unemployment duration and subsequent employment stability.' Journal of the European Economic Association. Forthcoming.

Topel, R.H., and M.P. Ward (1992) 'Job mobility and the careers of young men.' Quarterly Journal of Economics 107(2), 439-479

van den Berg, G.J., and B. van der Klaauw (2001) 'Combining micro and macro unemployment duration data.' Journal of Econometrics 102(2), 271-309

van den Berg, G.J., and M. Lindeboom (1998) 'Attrition in panel survey data and the estimation of multi-state labor market models.' Journal of Human Resources 22(2), 458-478

van den Berg, G.J., M. Lindeboom, and G. Ridder (1994) 'Attrition in longitudinal panel data and the empirical analysis of dynamic labour market behaviour.' Journal of Applied Econometrics 9(4), 421435 
Vishwanath, T. (1989) 'Job search, stigma effect, and escape rate from unemployment.' Journal of Labor Economics 7(4), 487-502

Vuong, Q.H. (1989) 'Likelihood ratio tests for model selection and non-nested hypotheses.' Econometrica $57(2), 307-333$

Zijl, M., G.J. van den Berg, and A. Heyma (2004) 'Stepping stones for the unemployed: the effect of temporary jobs on the duration until regular work.' IZA discussion paper No. 1241, Bonn 
Institut de Recherches Économiques et Sociales

Université catholique de Louvain

Place Montesquieu, 3

1348 Louvain-la-Neuve, Belgique 